\title{
Independent Technical Review of the C-400 Interim Remedial Project Phase I Results, Paducah, Kentucky
}

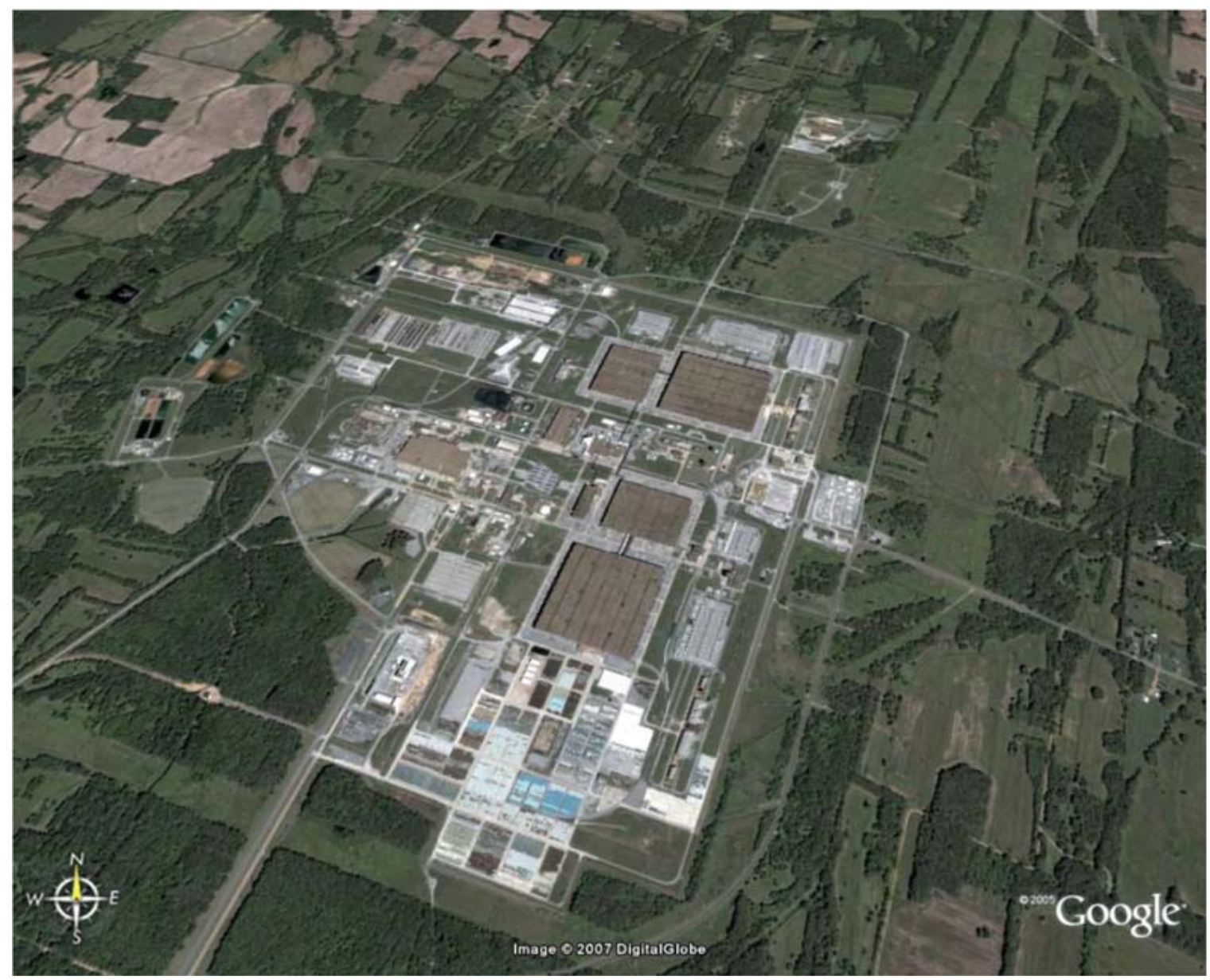

Prepared for: The U.S. Department of Energy Office of Environmental Management Groundwater and Soil Remediation Technology (EM32), Washington, DC

Prepared by: The DOE EM Center for Sustainable Groundwater and Soil Solutions, Savannah River National Laboratory, Aiken SC

October 2010 

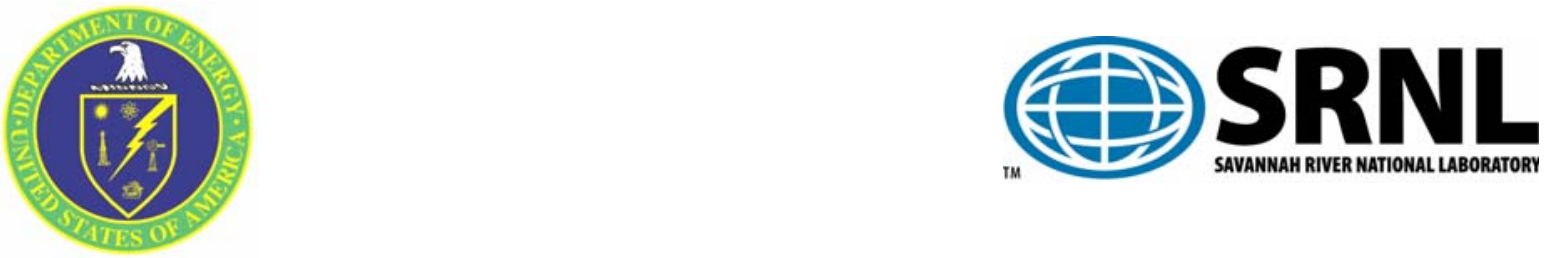

\section{Cover Photo: Oblique view overhead photograph of the Department of Energy Paducah Gaseous Diffusion Plant near Paducah KY. The TCE source area targeted for thermal treatment is located near the center of the photograph. .}

\section{DISCLAIMER}

This work was prepared under an agreement with and funded by the U.S. Government. While the authors have taken care in the preparation of this report, neither the U. S. Government or its employees, nor any of its contractors, subcontractors or their employees, makes any express or implied: 1. warranty or assumes any legal liability for the accuracy, completeness, or for the use or results of such use of any information, product, or process disclosed; or 2. representation that such use or results of such use would not infringe privately owned rights; or 3. endorsement or recommendation of any specifically identified commercial product, process, or service. Any views and opinions of authors expressed in this work do not necessarily state or reflect those of the United States Government, or its contractors, or subcontractors.

Printed in the United States of America

Prepared For

U.S. Department of Energy

Office of Engineering and Technology 
SRNL-STI-2010-00681

\title{
Independent Technical Review of the C-400 Interim Remedial Project Phase I Results, Paducah, Kentucky
}

\author{
Authors: \\ Dr.Brian B Looney (Technical Lead, Savannah River National Laboratory) \\ Dr. Joseph Rossabi (Redox-Tech, LLC) \\ Dr. Lloyd (Bo)Stewart (Praxis Environmental Technologies, Inc.) \\ Walt Richards (Performance Results Corporation)
}

Prepared for

Department of Energy (DOE) Office of Groundwater and

Soil Remediation

Washington, D.C.

October 2010

Technical content and coordination for this effort was provided by the Savannah River National Laboratory in conjunction with Contract No. DE-AC09-08SR22470 with the U.S. Department of Energy. 
\{blank page 


\section{Table of Contents}

Executive Summary

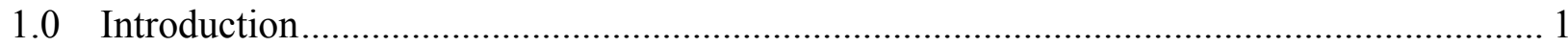

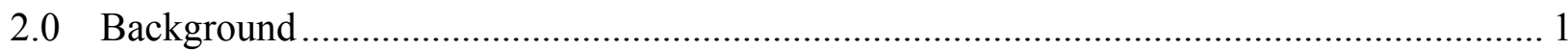

2.1 Previous Review Activities for Phase I C-400 Thermal Treatment .......................... 1

2.2 Phase I Plans ............................................................................................. 2

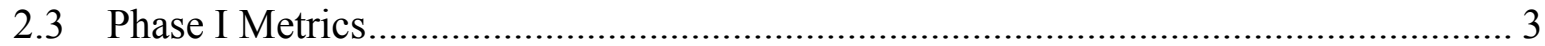

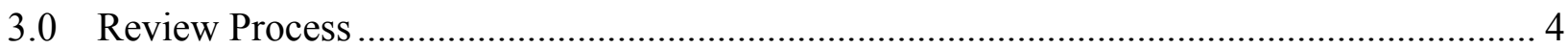

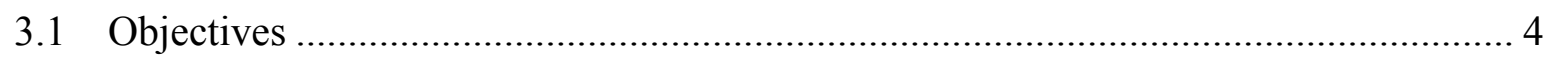

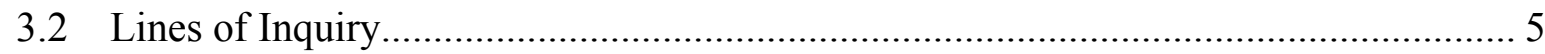

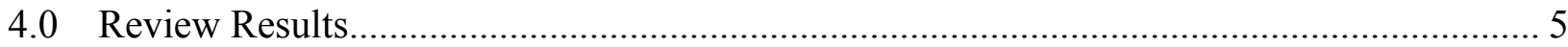

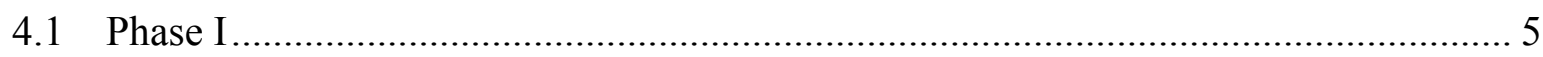

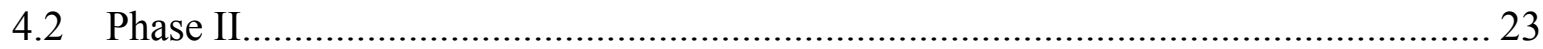

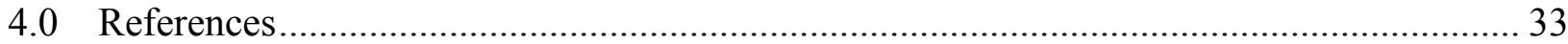

A Appendix - Independent Review Team Statement of Work ........................................ 35

B Appendix - Independent Review Team Members ….............................................. 38

C Appendix - Synopsis of Predeployment Phase I Recommendations and Responses ......... 46 


\section{Acronyms and Abbreviations}

\begin{tabular}{|c|c|}
\hline AFCEE & Air Force Center for Environmental Excellence \\
\hline $\mathrm{COC}$ & Contaminant of concern \\
\hline $\mathrm{C}_{\mathrm{s}}$ & Contaminant concentration in soil \\
\hline $\mathrm{cu}$ & cubic \\
\hline $\mathrm{cVOC}$ & chlorinated volatile organic compound \\
\hline $\mathrm{C}_{\mathrm{w}}$ & contaminant concentration in groundwater \\
\hline DNAPL & dense nonaqueous phase liquid \\
\hline DOE & U.S. Department of Energy \\
\hline EM-30 & $\begin{array}{l}\text { Environmental Management Office of Groundwater and Soil } \\
\text { Remediation }\end{array}$ \\
\hline EPA & U.S. Environmental Protection Agency \\
\hline $\mathrm{ft}$ & foot \\
\hline FY & fiscal year \\
\hline gal & Gallon \\
\hline gpm & gallons per minute \\
\hline $\mathrm{m}$ & meter \\
\hline MCL & maximum contaminant level \\
\hline MIP & membrane interface probe \\
\hline $\mathrm{MnO}_{2}$ & manganese dioxide \\
\hline msl & mean sea level \\
\hline $\mathrm{NaMnO}_{4}$ & sodium permanganate \\
\hline NAPL & nonaqueous phase liquid \\
\hline OEPA & Ohio Environmental Protection Agency \\
\hline PGDP & Paducah Gaseous Diffusion Plant \\
\hline PPPO & Portsmouth Paducah Project Office \\
\hline PRG & preliminary remediation goal \\
\hline RCRA & Resource Conservation and Recovery Act \\
\hline TCE & Trichloroethene \\
\hline TDY & temporary duty \\
\hline TOD & total oxidant demand \\
\hline VOC & volatile organic contaminant \\
\hline$w t \%$ & percent by weight \\
\hline yd & yards \\
\hline$\mu \mathrm{g} / \mathrm{kg}$ & micrograms per kilogram \\
\hline$\mu \mathrm{g} / \mathrm{L}$ & micrograms per liter \\
\hline
\end{tabular}




\section{Executive Summary}

The groundwater and soil in the vicinity of the C-400 Building at the Paducah Gaseous Diffusion Plant (PGDP), is contaminated with substantial quantities of industrial solvents, primarily trichoroethene (TCE). This solvent "source" is recognized as a significant challenge and an important remediation target in the overall environmental cleanup strategy for PGDP. Thus, the cleanup of the C-400 TCE Source is a principal focus for the Department of Energy (DOE) and its contractors, and for PGDP regulators and stakeholders. Using a formal investigation, feasibility study and decision process, Electrical Resistance Heating (ERH) was selected for the treatment of the soil and groundwater in the vicinity of C-400. ERH was selected as an interim action to remove "a significant portion of the contaminant mass of TCE at the C-400 Cleaning Building area through treatment..." with the longer term goal of reducing "the period the TCE concentration in groundwater remains above its Maximum Contaminant Level (MCL)."

ERH is a thermal treatment that enhances the removal of TCE and related solvents from soil and groundwater. The heterogeneous conditions at PGDP, particularly the high permeability regional gravel aquifer (RGA), are challenging to ERH. Thus, a phased approach is being followed to implement this relatively expensive and complex remediation technology. Conceptually, the phased approach encourages safety and efficiency by providing a "lessons learned" process and allowing appropriate adjustments to be identified and implemented prior to follow-on phase(s) of treatment. More specifically, early deployment targeted portions of the challenging RGA treatment zone with relatively little contamination reducing the risk of adverse collateral impacts from underperformance in terms of heating and capture.

Because of the importance and scope of the C-400 TCE source remediation activities, DOE chartered an Independent Technical Review (ITR) in 2007 to assess the C-400 ERH plans prior to deployment and a second ITR to evaluate Phase I performance in September 2010. In this report, these ITR efforts are referenced as the "2007 ITR" and the "current ITR", respectively. The 2007 ITR document (Looney et al., 2007) provided a detailed technical evaluation that remains relevant and this report builds on that analysis. The primary objective of the current ITR is to provide an expedited assessment of the available Phase I data to assist the PGDP team as they develop the lessons learned from Phase I and prepare plans for Phase II.

The current ITR developed the following consensus conclusions, or "lessons learned," related to Phase I.

- UCRS and uppermost RGA (50 to $70 \mathrm{ft}$ depth) were heated to the target temperature and the gas phase concentration and mass removal decreased over time stabilizing at relatively low levels (i.e., "asymptosis"). If confirmatory borings in the UCRS indicate significant TCE source reduction, then Phase I can be considered successful in achieving the regulatory/technical objectives in this zone. However, additional mass may be removed at relatively low cost by continuing soil vapor and groundwater extraction until the soil cools after terminating the heating. 
- Temperature goals were generally not achieved in the RGA (particularly in the deep RGA from 70 to $100 \mathrm{ft}$ depth) during Phase I. The data confirm that in a high permeability - high flow aquifer, thermal remediation is inefficient as a significant proportion of the applied energy was lost from the target zone. The inefficiencies were exacerbated by periods when the electrodes were not powered due to operation problems. In general, the complex engineering and operational efforts focused on minimizing heat loss and distributing the energy throughout this challenging subzone were ineffective. Analogously, the data indicate the Phase I system did not adequately control contaminant migration from the RGA treatment zone. These topics were specifically identified and discussed in detail in the earlier (2007) review and will not be repeated here.

- Phase I costs, even when generously adjusted/reduced to account for water treatment infrastructure that is available for future remediation activities, were approximately $\$ 2500$ per cu yd. Based on the literature (e.g., Looney et al., 2007 Appendix E and Baker 2006) and the experience of the ITR panel members, these are the highest unit costs ever reported for a full scale thermal remediation. Such high costs suggest a lack of focus on important project management controls and the need for a renewed commitment to cost effectiveness as the site moves into future phases of clean-up.

The ITR developed the following consensus conclusions related to the potential changes that were "proposed" for meeting a commitment of using ERH exclusively for heating in the RGA during Phase II - the documents provided to the ITR were developed primarily by the Phase I ERH contractor McMillan McGee $\left(\mathrm{Mc}^{2}\right)$.

- The primary basis for the suggested system changes (required to heat the RGA using ERH) was new modeling runs. The modeling concentrated on improved heating in the RGA and better control/capture of heat and contaminant. Importantly the current ITR concluded that the modeling to support Phase II heating of the RGA is inadequate - the weaknesses and deficiencies identified by the 2007 ITR in the Phase I model were not appropriately evaluated and corrected. Further, the contractor did not avail themselves of the obvious opportunity to convincingly validate and calibrate their model based on the detailed energy, temperature and pressure dataset collected during Phase I.

- Application of a simplified scoping model/calculation to predict ambient groundwater velocities in the RGA from Phase I field temperature data was not valid.

- The modifications for Phase II that were indicated by the modeling (more electrodes, closer spacing, upgradient water extraction, higher voltages, higher water and vapor extraction, injection of preheated water, increased saline injection, etc.) would potentially increase costs dramatically for Phase II.

- The draft plans are indefensibly expensive, not supported by a clear conceptual basis or validated model, and difficult to implement. 
Based on our review, the current ITR team developed the following overarching conclusions/recommendations:

- The ITR recommends discontinuing the Phase I heating operations - the regulatory commitments and objectives appear to be met in the UCRS and continued heating in the RGA is contraindicated. However, as stated below, continued extraction is recommended during cooling to garner benefits afforded by the residual heat in the target soils.

- Plans should be initiated to implement a modified Phase II (see below). In the interim between Phase I and Phase II, vapor and groundwater extraction should be continued, with changes implemented to reduce operating costs and with appropriate allowances for turn-off, as needed, to allow for Phase II mobilization and system alterations.

- Heating of the UCRS appears feasible and we recommend developing plans for efficient and effective Phase II ERH deployment for this zone.

- ERH (or any of the other thermally enhanced removal technologies) is poorly matched to the RGA conditions in the vicinity of the C-400 building - The ITR recommends that heating technology be eliminated from Phase II for this particular zone. Instead, the ITR recommends that the PGDP project team and their regulators and stakeholders, address the TCE source in the RGA using a technology that is better matched to the RGA target zone - one that will lead to better performance, lower costs, reduced collateral impacts (e.g., energy use), reduced drilling, etc.

- Specific technologies that take advantage of high permeability saturated RGA conditions include: oxidation using chemical reagents, solubilization using cosolvents or surfactants, and others. The ITR recommends identification and implementation of a more appropriate technology for addressing the Phase II RGA TCE source material.

- As an interim Phase II support action, the current ITR recommends modifying the existing water treatment infrastructure for Phase II support (to reduce unnecessary costs) and implementing pump and treat of contaminated groundwater from the RGA in the Phase II (southeast) C-400 target zone. Preliminary calculations indicate that performing pump and treat in this zone would remove contamination at rates that are on par with the Phase I RGA system while substantially reducing the potential for adverse impacts.

- Clear plans should be developed and implemented to assure that project management systems are in place to control costs and to identify and correct cost escalation issues. For example, no compelling basis exists for a sole source contract to heat the UCRS in Phase II. The ITR recommends demobilizing the existing heating equipment and performing a competitive rebid process for future work - this should be initiated as soon as possible.

The ITR encourages all parties and employees involved in this cleanup to focus on their important roles in making this difficult project a success - this type of "ownership society" is key to implementing a Phase II in a safe-effective-efficient manner that maximizes the removal of the TCE source while controlling expenditures. 


\subsection{Introduction}

The U. S. Department of Energy (DOE) is operating an electrical resistance heating (ERH) system in areas near the southwest corner and east of the C-400 Cleaning Building at the Paducah Gaseous Diffusion Plant (Phase I) to enhance the removal of solvent contamination in the underlying soil and groundwater. DOE is using the results of Phase I, the data and "lessons learned," to develop/refine plans for remediation of the more highly contaminated areas near the southeast corner of the C-400 Cleaning Building (Phase II). Current plans and commitments for this remediation are to use an expanded implementation of the same heating technology. To assist in this effort, DOE assembled an independent team of scientists and engineers with expertise in groundwater remediation and treatment, engineering, design, and treatment system installation and operation to provide an expedited review of Phase I results and Phase II plans. The review team consisted of Dr. Brian Looney (Savannah River National Laboratory), Dr. Lloyd "Bo" Stewart (Praxis Environmental), Dr. Joe Rossabi (RedoxTech LLC), and Mr. Walt Richards (PRC Paducah). Appendix A provides information on the background of the team members.

\subsection{Background}

\subsection{Previous Review Activities for the C-400 Thermal Treatment}

Several of the current Independent Review Team (ITR) members participated in an earlier review of the then planned thermal treatment for this site, Review Report: Building C-400 Thermal Treatment 90\% Remedial Design Report and Site Investigation, PGDP, Paducah Kentucky (Looney et al., 2007). In the earlier review, the team members highlighted a substantial number of key issues and provided specific recommendations. In particular, the earlier review team expressed concern about the ability to heat the deep portion of the highly permeable Regional Gravel Aquifer (RGA) and found the supporting models "unconvincing." The team also urged the Paducah project team to develop realistic and technically based performance metrics, perform additional characterization, develop more robust and diverse contingencies, reduce costs, and consider numerous engineering and logistics recommendations. One of the most important recommendations from the earlier team was to use a phased approach for the planned C-400 cleanup activities. This would provide an opportunity to assess the performance of ERH in this challenging setting, and to use the performance during Phase I to refine, optimize or alter activities in the follow on phase(s). The Paducah team and their contractors considered the identified issues and recommendations and made some modification (See Appendix C) - most importantly, they structured the project in two phases. The results of the current ITR activities reflect, and are informed by, the 2007 report; the current team members would like to express their recognition of, and appreciation for, the important contributions of all of the members the earlier team and to specifically recognize those individuals who participated in the earlier team, but who are not represented in our current expedited effort: Dr. Eva Davis, US Environmental Protection Agency (EPA), Dr. Jed Costanza (EPA) and Dr. Hans Stroo (HGL, Inc). 


\subsection{Phase I-Plans}

Thermal treatment, specifically ERH, was selected as an interim action for treating residual TCE sources in the soil and groundwater in the vicinity of C-400 (DOE, 2005a). The plans for ERH deployment were documented in the Remedial Action Work Plan (RAWP) (DOE, 2008a) and the Remedial Design Report (RDR) (DOE, 2008b). These plans were implemented by onsite and contractor personnel. Implementing the remediation in two phases was a key element described in the RAWP:

"A phased deployment of ERH will be implemented. The first phase (Phase I) will implement the design presented in the RDR, referred to as the base design, in the southwest and east treatment areas. In addition to removing VOCs from these areas, another important objective of Phase I will be to evaluate the heating performance of the base design through the Regional Gravel Aquifer down to the McNairy Formation interface in the southwest treatment area. Treatment in the east treatment area involves only the Upper Continental Recharge System."

The RAWP also describes the role of Phase I in developing contingencies and in evaluating capture of the vapor recovery system and hydraulic containment in the groundwater. Figure 1 provides a graphical overview of the three TCE source areas (southwest, southeast, and east) that were identified using membrane interface probe (MIP) characterization, operational records, and historical data (DOE 2008a and DOE $2008 \mathrm{~b}$ ). Figure 1 also indicates the relative quantities of TCE source mass in the different areas and the allocation of the source areas to the Phase I (southwest and east) and Phase II (southeast) treatment campaigns. Deployment of Phase II was projected to follow Phase I with modifications to be made based on data from Phase I and lessons learned.

Because of the significant uncertainties related to heating in the high permeability RGA (Looney et al., 2007), a target RGA treatment zone with relatively low TCE source mass was selected for Phase I (Figure 1). This decision deferred ERH treatment of the southeast treatment area (with substantially higher TCE source mass projected in the RGA) to Phase II, mitigating the potential technical risk associated with underperformance in heating and/or hydraulic containment (i.e., reducing the potential for release and mobilization of large amounts of TCE source to the groundwater). Because a RGA volume with relatively low TCE source mass was targeted, the expected Phase I mass removal from the RGA was relatively small compared to the projected mass removal from the UCRS for Phase I and small compared to the projected mass removal for both the RGA and UCRS for Phase II. Note that the deployment of ERH in the shallower UCRS was considered to pose less technical risk (Looney et al., 2007) and the Phase I UCRS target volume was projected to contain a significant mass of TCE (DOE 2008a and 2008b). 


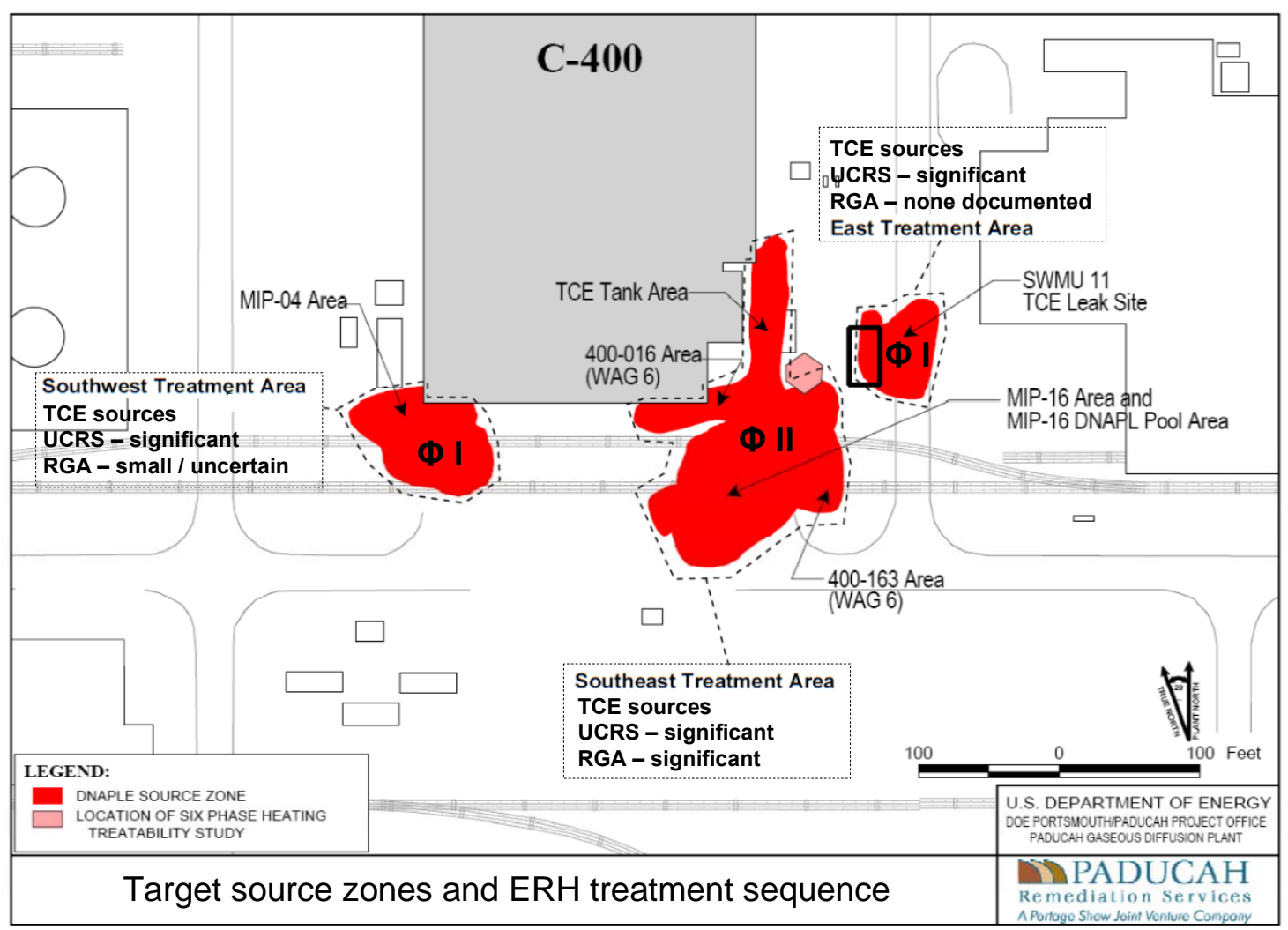

Figure modified from RDR (DOE 2008b)

Figure 1. C-400 vicinity DNAPL sources targeted for ERH treatment. The figure documents the planned sequence for Phase I ( $\Phi$ I) and Phase II ( $\Phi$ II) and summarizes the relative quantities of DNAPL source mass in the different zones.

\subsection{Phase I-Metrics}

In working toward risk-based end-state goals for PGDP, actions to mitigate the known contaminant sources around Building C-400 have been identified as a key activity in PGDP environmental management strategy documents (e.g., DOE, 2005b). In response, an interim Record of Decision (ROD) (DOE 2005a) was developed to address TCE, a primary C-400 contaminant. The ROD identified thermal treatment as the selected technology and established the following objectives for treatment:

o It will contribute to the final remediation of the Groundwater OU by removing a significant portion of the contaminant mass of TCE and other VOCs at the C-400 Cleaning Building.

O It will reduce the period of time that TCE concentration in groundwater remains above its Maximum Contaminant Level (MCL), and meets the statutory preference for attaining permanent solutions through treatment.

o It is not expected to meet the MCL in groundwater for TCE, but satisfies the requirements set forth in 40 CFR 300.430(f)(1)(ii) for interim measures that will become part of the total remedial action that will attain applicable requirements (ARARs). 
o It will be cost-effective based upon the estimates available at the time of the ROD.

o It will permanently remove a significant portion of the TCE near the C-400 Cleaning Building area through treatment, but will result in hazardous substances, pollutants, or contaminants remaining on-site at levels precluding unlimited use and unrestricted exposure.

o It meets the regulatory preference for remedies that employ treatment as a principal element of the remedy that permanently and significantly reduces toxicity, mobility, or volume of hazardous substances, pollutants, or contaminants

Note that these strategic objectives appropriately recognize that ERH will not achieve final cleanup goals for solvent sources at C-400 and, instead, attempt to define an appropriate role for the technology as an interim action intended to remove a significant quantity of source mass within the context of a longer term sequence of remedial activities. The shut off criteria for the Phase I interim action, as stated in the Record of Decision (ROD) (DOE 2005a), are to operate the ERH system "until monitoring indicates that heating has stabilized in the subsurface and that recovery of TCE, as measured in the recovered vapor, diminishes to a point at which further recovery is at a constant rate (i.e., recovery is asymptotic). At asymptosis, continued heating would not be expected to result in any further significant reduction of toxicity, mobility, or volume of the zone of contamination." Section 3.3 of the Remedial Design Report presents the negotiated criteria for ceasing operations, which address the ROD goals of achieving stabilized heating of the subsurface and asymptotic recovery of TCE. The RAWP further indicated that groundwater TCE concentrations and pulsed (rebound) tests would be used to supplement the temperature and vapor concentration metrics. The RDR (DOE 2008b) defined asymptotic recovery in more detail and provided additional detail regarding criteria for ceasing Phase I ERH operations.

\subsection{Review Process}

\subsection{Objectives}

The overarching objectives of the ITR are to review C400 thermal treatment Phase I results and Phase II plans. This review was performed in an expedited manner in an attempt to provide independent information and assessment on these topics. The review team was provided available reports and data on Phase I and preliminary plans and modeling related to Phase II. Because of the expedited schedule, the review team focused primarily on overarching issues related to technical performance and project implementation. The team did not perform a detailed scientific or engineering evaluation. The focus of the effort was to provide information to DOE and the PGDP project team, regulators and stakeholders to assist in environmental management decisions and formulating plans for Phase II activities. 
In summary form, the basis, goals and objectives for this ITR effort were:

- Basis:

- The C-400 source zone clean-up is a large-important project to DOE

- The unique setting yields a complex and challenging application of the selected thermal technology

- Goals and objectives:

- Provide input to the PGDP team from independent technical experts

- Assess the data and performance from Phase I and the plans for Phase II

- Support DOE and regulators as plans are being put in place for Phase II

- Supplement the 2007 ITR

The team would like to express their appreciation to the DOE PPPO and to the technical and management staff at PGDP for their support and for their responsiveness in providing the data requested (when available).

\subsection{Lines of Inquiry}

To meet the review objectives, the ITR identified the following lines of inquiry.

- For Phase I: temperature performance, concentration and mass reduction performance, project implementation, cost and project structure and lessons learned.

- For Phase II: summary of proposed activities, ITR review of proposed activities, ITR identified alternatives for consideration

The following section is organized according to these lines of inquiry.

\subsection{Review Results}

\subsection{Phase I:}

Temperature Performance

As shown in Figure 2, the Phase I treatment areas were fitted with ERH electrodes, water and vapor monitoring wells/piezometers, digital temperature monitoring systems ("digiTAMs"), and digital pressure monitoring systems ("digiPAMs"). The digital monitoring systems provided measurements from the base to the top of the targeted treatment zone at regularly spaced depth intervals (e.g., every three feet). Much of the data collected by the monitoring system (as well as information about the status and power levels at the ERH electrodes) was made available to the PGDP project team and others via secure web access (http://www.mcmillan-mcgee-data.com/paducah). The web data portal was provided by the ERH contractor $\left(\mathrm{MC}^{2}\right)$ and the data were generally updated daily. The IRT found the data portal to be useful, found the interface to be attractive and intuitive, and commends the PGDP project team and $\mathrm{MC}^{2}$ for implementing this relatively useful communication tool (note that the portal focused only on ERH - 
similar systems were not in place for contaminant concentration and removal data and data related to the vapor and water treatment systems).

The primary thermal objective for Phase I was to achieve target temperatures throughout the heated zone. The target temperatures were set at levels that approach the boiling point of water as a function of depth/pressure (achieving this temperature throughout the zone is a surrogate indicator that bulk TCE source solvent has been removed because the presence of such material would stall the temperature below this level). The middle and bottom panels on Figure 2 show snapshots of example temperature distributions in the UCRS and the deep RGA after the temperatures has reached a "steady state." It is

Key Points:

During Phase I...

The UCRS was heated to target temperature

Temperature goals were generally not achieved in the RGA. clear from this figure that there was a significant thermal performance difference between the UCRS and the RGA. Heating in the UCRS was relatively effective and the heat was distributed throughout the zone. Conversely, the heating in the SW Area deep RGA was less effective and localized around the electrodes.

Note that the contour plot for temperatures in the deep RGA almost certainly overstates the size of the hot areas around the electrodes because there are insufficient numbers of digiTAMs to control for the cool temperatures occurring between the various pairs of adjacent electrodes - everywhere there is a digiTAM between electrodes, the picture cools to green while areas without such control allow the warm colors to coalesce. Further, the extent of the warmest (white and pink) areas around the electrodes is not substantiated by data (these areas were not monitored) and the depiction is a function of the contouring algorithms that may not represent actual conditions. Despite these standard limitations associated with machine contouring (a necessity to allow posting and rapid sharing the data on the project portal), the images provide a generally accurate broad conceptual picture of RGA heating performance. The plots clearly indicate that heating in the lower portion of the RGA was ineffective - with target temperatures extending less than 5 radial feet from the electrodes. The uppermost 3 to 6 feet of the RGA (layer map not shown in Figure 2) exhibited more uniform heat suggesting that the localized heating around the electrodes in the this permeable aquifer resulted in upward convection of hot water and steam and lateral spread at the RGA UCRS interface. These heat distributions and patterns are fundamental to the conditions of the RGA and are consistent with the 2007 ITR predictions and comments (Looney et al., 2007). 
Note that the members of the ITR generally support the use of thermal remediation of source zones in appropriate settings and that our conclusions about the ineffectiveness of heating in the RGA should not should not be interpreted as a general assessment of this important technology. A more detailed review of the temperature data document the delivery of large amounts of energy/heat during Phase I and measurable heating in the RGA. The Phase I temperature data from initial startup and into June 2010 indicated an increase in temperatures in the lower RGA, with saline injection at the electrodes required to maintain power levels at the electrodes (to maintain high power levels at $>12$ $\mathrm{kW} / \mathrm{electrode}$ ). Saline injection appeared to become ineffective in mid- to late- June, possibly due to saline injection delivery problems to the deeper electrodes. Saline injections were suspended in early July 2010. The system also experienced periods of equipment problems during which the electrodes were not powered. Nonetheless, after extended operation, the temperature distribution reached a "steady state" that closely matched the theoretical pattern predicted from analytical models based only on aquifer properties (van Lookeren, 1983). Thus, even though the Phase I data showed the RGA was being heated to some degree, it also provided convincing information that thermal remediation in this setting may

Key Point:

The temperature data confirm that thermal remediation technologies such as ERH are not well suited to uniform heating in high permeability and high flow aquifers. be constrained by fundamental process limitations.

Another important aspect of the thermal performance can be assessed by considering the energy balance. How does the energy input to the system balance with the temperatures? If energy (and by analogy mass) is being lost, where is it going? Data and time limitations precluded the current ITR from a comprehensive energy balance analysis, but a screening of the available data provides important information to help understand Phase I temperature performance. 


\section{PHASE I TEMPERATURE PERFORMANCE \\ ||}

\section{LAYOUT}
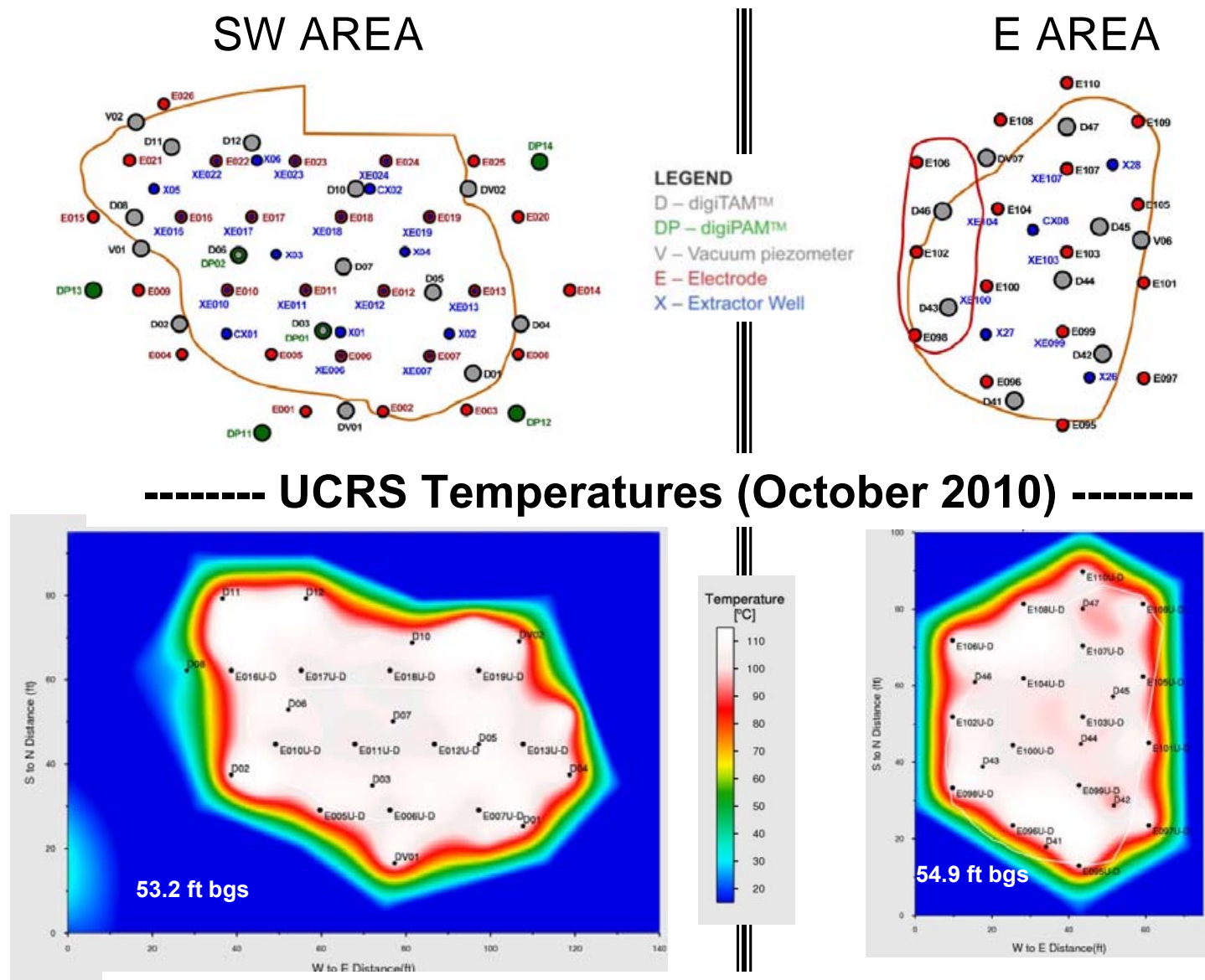

RGA Temperatures (October 2010)
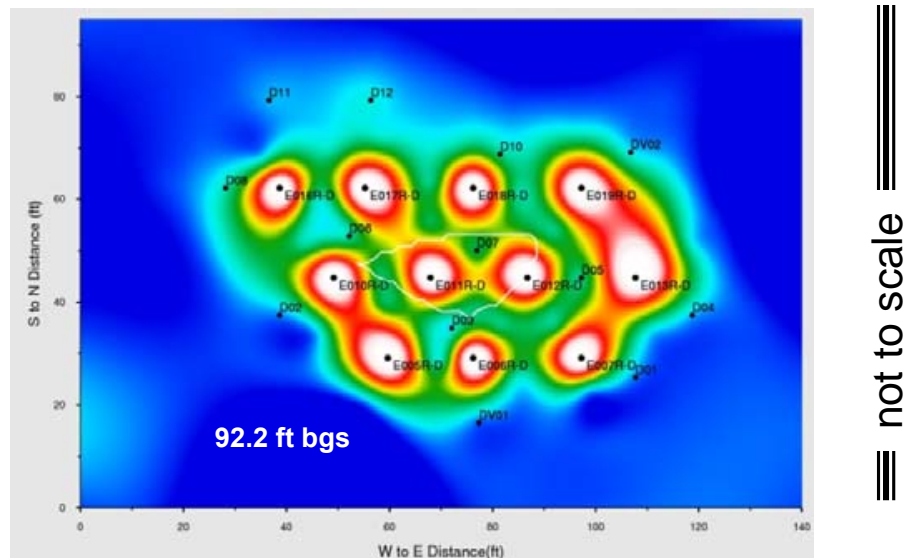

Figure 2. Phase I C-400 thermal treatment site layout and examples of "steady state" temperature maps for the UCRS and deep RGA (data are from the ERH project data portal) 
According to the information provided on the project data portal, the soil volume targeted for heating in the southwest area was $163,401 \mathrm{ft}^{3}$ in the vadose zone and 15,291 $\mathrm{ft}^{3}$ in the saturated zone. The water table was located at a depth of about 55 feet below the surface and the saturated zone treatment extended to 80 feet. The energy transferred to the Southwest Area during Phase I, as of 1-Oct-10, was $\sim 1,750,000 \mathrm{kWhr}$ into the UCRS and $\sim 670,000 \mathrm{kWhr}$ into the RGA. The energy required to bring a unit of vadose zone soil to saturated steam temperature (i.e., to the boiling point) is approximately $1.5 \mathrm{kWh} / \mathrm{ft}^{3}$. In the saturated zone, the energy value is roughly $2.0 \mathrm{kWh} / \mathrm{ft}^{3}$. Assuming the UCRS roughly corresponds to the vadose zone for screening purposes, the energy transferred per target soil volume was about $10.7 \mathrm{kWh} / \mathrm{ft}^{3}$. This energy input is above the minimum required to bring the vadose zone soil to saturated steam temperature (i.e., to the boiling point). The ITR attributes the excess energy requirement to the power needed to balance water injected into the electrodes, higher energy requirements associated with any saturated UCRS materials, heat loss from steam and water spread, heat loss from conduction, and the associated power needed to hold the zone at temperature over time. Importantly, the UCRS has significantly lower permeability and lower saturated flow compared to the underlying RGA and the UCRS exhibited more effective and even heating. Based on the above assumptions, we can calculate the ratio of energy actually applied to the UCRS to the minimum theoretical value $(10.7 / 1.5 \cong 7)$ for a zone that was effectively heated. This ratio, in turn may serve as a rough guide, or scoping value, to assess if significantly more heat loss occurred in the RGA.

The energy required to bring a unit of saturated zone soil to saturated steam temperature (i.e., to the boiling point) is approximately $2.0 \mathrm{kWh} / \mathrm{ft}^{3}$ if the water is stagnant. Assuming the saturated zone volume corresponds roughly to the RGA, the energy transferred per target soil volume was about $44 \mathrm{kWh} / \mathrm{ft}^{3}$. This energy input is 22 times the theoretical minimum required to bring the saturated zone soil to saturated steam temperature (i.e., to the boiling point); however, this quantity does not account for the influx of ambient groundwater from natural gradients. Based on the stagnant water energy balance, the energy transfer would appear to be more than sufficient to heat the RGA but temperature monitoring indicated limited heating occurred in the soil below 70 feet bgs near the top of the RGA. While insufficient data were provided on water injection and extraction to fully assess the energy balance, the excess energy applied to the RGA was $22 x$ the theoretical minimum compared to "reference" value of 7x calculated for the UCRS. The data suggest that the majority of the energy introduced to the RGA was lost to flowing groundwater. Energy losses from the heated volume were further exacerbated by operational issues such as power outages and interruptions in groundwater extraction (note that the target extraction to injection ratio was 1.7 (i.e. $70 \%$ more fluids were extracted than were injected). Thus, the energy balance indicates that heat (and contaminant to the extent it was present in the lower RGA in the SW area) migrated downgradient and outside beyond the target soil volume during Phase I. 
Energy Balance in the East Treatment Area -

The soil volume targeted for heating in the East Area was $60,494 \mathrm{ft}^{3}$ in the vadose zone and 15,291 $\mathrm{ft}^{3}$ in the saturated zone. The water table was located at a depth of about 55 feet below the surface and the saturated zone treatment extended to 60 feet. The energy transferred to the East Area during Phase I was $\sim 1,200,000 \mathrm{kWh}$ into the UCRS. The RGA was not treated in the East Area. The total energy transferred per target soil volume was therefore about $16 \mathrm{kWh} / \mathrm{ft}^{3}$. The energy required to bring a unit of vadose zone and saturated zone soil to saturated steam temperature (i.e., to the boiling point) is approximately 1.5 to $2.0 \mathrm{kWh} / \mathrm{ft}^{3}$. The energy applied to the east treatment area is about 10x the minimum theoretical value, similar to ratio calculated for the UCRS in the SW area.
Key Points:

The energy applied to heat and hold the UCRS at target temperature was about 7 to 10 times the theoretical requirement. The energy applied to the RGA was about 22 times the theoretical requirement while Phase I RGA temperatures stabilized below target values. This suggests that water flowing through the permeable RGA is removing the majority of the applied energy from the treatment zone.

\section{Concentration and mass reduction performance}

Mass Removal during Phase I -

At the time of the ITR visit, the cumulative mass removal during phase I operations was approximately 6,548 lbs (535 gallons) of TCE. This source TCE was removed from the subsurface in the East and Southwest Treatment Areas. The solvent was collected in the treatment system in the T-107 tank or sorbed to the activated carbon beds. The PGDP operations teams reported approximately 30 gallons of TCE on the activated carbon (based on concentration measurements in the inlet stream minus the outlet stream) and just over 500 gallons of net TCE in the T-107 tank under a layer of water which is pumped off periodically for reprocessing through the water treatment system. The TCE was sampled and analyzed recently and determined to be primarily TCE. A key cocontaminant, ${ }^{99} \mathrm{Tc}$, was measured in the collected DNAPL/TCE solvent with an activity near the method detection limit (approximately $12 \mathrm{pCi} / \mathrm{L}$ ). Data for other potential hydrophobic co-contaminants discussed in Looney et al., (2007) were either not measured in the solvent phase and/or not reported to the ITR. Based on the available information, the solvent may be suitable for recycle instead of disposal/destruction as a hazardous waste. If recycle is viable, such a disposition path represents a relatively benign and more sustainable option.

The measured collection of approximately $6,548 \mathrm{lbs}$ of TCE during the Phase I ERH in the SW and E treatment areas was a significant source of concern at the time of the ITR visit. The initial estimates of TCE mass - approximately $285,781 \mathrm{lbs}$ (23,350 gallons) -were more than 40 times higher than the amount of TCE actually removed during Phase I 
- approximately 6,548 lbs (535 gallons). Concerns related to the large discrepancy between the "conservative" original estimates of mass and the actual removal were heightened when a retrospective calculation of mass was generated using limited soil core data - that estimate was approximately $5 \mathrm{lbs}$ (61 gallons). In response to these issues, the ITR examined the estimates and uncertainties.

Uncertainty in Initial Mass Estimates -

In the August 2007 Review Report (WSRC-STI-2007-00427), the Independent Technical Review (ITR) team recommended collecting enough soil and groundwater concentration data to calibrate the Membrane Interface Probe's (MIP) response to TCE (Recommendations 5.1.1a and 5.1.1b). Unfortunately, the MIP calibration was not performed so an alternate approach was used to incorporate the extensive MIP data into an estimate of residual TCE at the site. Appendix A in the Remedial Design Report (DOE/LX/07-0005\&D2/R1, July 09, 2008) describes the method and calculations used to develop TCE mass estimates for the southwest target area based on MIP data.

MIP data were collected from 51 locations and NAPL presence or absence at the MIP location was correlated to specific detector threshold values. The highest MIP values over a five foot interval were assigned to that interval. If these MIP values exceeded the threshold value, TCE NAPL was posited for that interval. The five foot intervals were then combined into 20 foot vertical sections. If soil sample data were available (e.g., for a few 20' to 40' and 40' to 60' data), these data were evaluated with the MIP data to determine NAPL sections. At each NAPL section, a saturation value was assigned assuming a cylinder of residual NAPL saturation (posited at $30 \%$ assuming maximum values from a 1991 document written by B.H. Kueper) which decreased logarithmically with radial distance from the cylinder until reaching a minimum saturation value of $1 \%$. The volume of NAPL was then calculated (Attachment A6 of the Remedial Design Report) based on the assumed TCE saturation values. From this analysis, a volume of 23,100 gallons of TCE was estimated to be in the southwest treatment area. In the east, at the SWMU 11 TCE Leak Site, calculations were based on analyses of soil core from Boring 011-005 resulted in a total estimated volume of 250 gallons (3060 lbs) of TCE. Thus the total TCE solvent volume initially calculated for the Phase I treatment zones (SW and E) was approximately 285,781 lbs (23,350 gallons)

From experience with residual DNAPL saturation encountered at other sites, $30 \%$ residual TCE saturation (approximately $100 \mathrm{~g} / \mathrm{kg}$ ) is exceptionally high and rarely encountered at sites, making the initial estimates unrealistically high. More commonly found residual saturation values of TCE are between 1\% and $2 \%$. Using a value of 1\% residual saturation for the target volume in the southwest area calculated in Appendix A of the Remedial Design Report, a residual TCE volume of approximately 2,650 gallons $(32,433 \mathrm{lbs})$ of TCE is calculated.

For the east, the measured TCE saturation of 3\% occurring between the depths of 28 ' and 32' bgs was used to calculate total TCE mass assuming a radial extent of approximately 15.7 feet around Boring 011-005. This extrapolated mass (3060 lbs) based on the sample 
data is similar in magnitude to the TCE mass actually removed (3427 lbs from soil vapor extraction data in the east as of 9/26/10). This provides an additional line of evidence that the thermal treatment may be effectively treating the UCRS (particularly since some additional mass removed may originate outside of the target volume). If confirmed by post-treatment soil sampling results, the ITR technical assessment would be that the UCRS was effectively remediated in Phase I.

Using the more realistic NAPL saturation based estimate for the SW area and the actual mass removed in the East area, the estimated mass of TCE in the Phase I treatment zone is $35,860 \mathrm{lbs}$ (2,930 gallons). While this lower value represents a more realistic estimate, the available data do not support the development of a defensible estimate of initial TCE mass in the Phase I treatment zones.

In response to the poor mass balance, a supplemental calculation was performed based on soil core data. During the 2007 ITR (Looney et al., 2007), the team recommended collecting enough soil and groundwater samples to calibrate MIP values and to refine the treatment volume. On installation of electrodes and monitoring equipment, a limited number of soil samples in the southwest area were collected from the rotasonic drilled boreholes. These samples were insufficient for calibrating the MIP data. The samples were used to independently estimate the mass of TCE in the southwest area. Approximately $5 \mathrm{~g}$ samples were collected approximately every 10 to 20 feet using Encore samplers and analyzed by commercial laboratory. Sample selection was guided by screening the collected soil with a portable photo ionization detector (PID). The total volume of TCE estimated by this method was approximately 5 gallons (61 lbs), which is a significant underestimate of the residual contaminant mass. There are several negative biases in collecting samples in this manner. Volatile compounds in Rotasonic core can be lost if a large amount of energy (sonic converted to heat) is required for drilling a particular depth interval. Compounds can also be lost if a large amount of water is used during drilling (from flushing the sediments). In addition to losses incurred by drilling, organic contamination is generally found in discrete, and often small, sections of the subsurface. Collecting approximately $5 \mathrm{~g}$ samples every 10 feet or more will rarely be adequate to accurately represent contaminant distribution. Finally, using only measured groundwater concentration values

Key Points:

The initial large estimates of TCE mass in the soil and groundwater in the SW treatment area at the C-400 Building were based on unrealistically high DNAPL saturation assumptions and were too high. Later estimates using limited and insufficient soil samples were biased low. The ITR concluded that, despite the large amount of characterization at this site, data do not exist to generate a definitive and fully credible pretreatment mass estimates. However, using more centrist assumptions, the ITR calculated an order of magnitude estimate for Phase I starting mass of 35,860 lbs (2,930 gallons) for the combined SW and East treatment areas. The estimates for the east treatment area were performed using a different approach and appear reasonable. 
(approximately $50 \mathrm{mg} / \mathrm{l}$ ) and the volume of the saturated zone in the southwest area (approximately $3254 \mathrm{~m} 3$ ), approximately 10.5 gallons (128.5 lbs) of TCE can be found in the groundwater alone.

As described previously, the majority of energy introduced into the RGA in the Southwest Area was lost to groundwater that migrated downgradient from the target volume indicating dissolved contamination was lost with it. While this phenomenon had minimal adverse impact during Phase I (because of the relatively low TCE content in the RGA), such transport has important implications when planning for Phase II in an area that has significantly higher TCE content in the RGA. Application of ERH in the RGA of the Southeast Area would have the potential to mobilize significant contaminant mass and any contaminants mobilized by the heating would tend to migrate beneath the C-400 Building where there is limited capability for extraction and treatment. For example, if the groundwater velocity is six feet per day and heating yields a dissolved phase TCE concentration of $50 \mathrm{mg} / \mathrm{L}$, the rate of TCE transport away from the Southeast Treatment Area would be on the order of 10 to 15 pounds per day. This is an important topic that should be weighed by the PGDP team as they plan for Phase II. This finding suggests that ERH be eliminated as a treatment for the RGA in the SE area or that clear and aggressive design action be implemented to assure that control and capture are maintained in the high permeability RGA.

\section{Mass Captured During Initial Soil Vapor Extraction (SVE) -}

The 2007 ITR review (Looney et al., 2007) recommended operating SVE and pump-andtreat for extended periods prior to energizing the subsurface. The extended operation was to allow equipment shakeout and to provide a baseline of contaminant removal rates without heating. Unfortunately, Phase I operations without heating were performed for only a few days. Nonetheless, the data can be used to suggest the value of heating the subsurface on contaminant removal rates. The TCE removal rates before heating and the maximum rates measured during heating were:

$$
\begin{array}{ll}
\text { Southwest SVE }=12-23 \mathrm{lb} / \text { day } & \text { (Maximum during heating }=52 \mathrm{lb} / \text { day) } \\
\text { East SVE }=\sim 1.5 \mathrm{lb} / \text { day } & \text { (Maximum during heating }=141 \mathrm{lb} / \text { day) } \\
\text { Groundwater Extraction = } 17 \mathrm{lb} / \text { day } & \text { (Maximum during heating }=17 \mathrm{lb} / \text { day) }
\end{array}
$$

If we calculate hypothetical mass recovery for six months of operation at the initial, unheated, SVE and groundwater extraction mass recovery rates (assuming the concentrations remained constant), the performance would be as follows:

Hypothetical unheated Southwest $\mathrm{SVE}=3,000$ pounds (255 gallons)

Hypothetical unheated East $\mathrm{SVE}=270$ pounds (22.5 gallons)

Hypothetical unheated Groundwater Extraction $=3,000$ pounds (255 gallons)

Hence, pump-and-treat in both areas, without heating, had the potential to recover an TCE at rates that were similar in magnitude to the heated Phase I performance. However, the comparison reveals that heating with SVE in the Southwest area was moderately 
effective and in the East Treatment Area was very effective. The general conclusion is that heating with SVE in the vadose zone was generally effective while pump-and-treat alone may have worked nearly as well as ERH in the saturated zone. ERH is accompanied by water injection at the electrodes such that dilution may have occurred in the extracted groundwater as evidenced by the decrease in mass removal rate via groundwater extraction with the onset of heating and water injection.

\section{$\underline{\text { Response of Soil and Groundwater Concentration/Flux }}$}

As the Phase I UCRS (SW and E) and RGA (SW) were heated, contaminant removal increased in the vapor phase and then declined as expected (see Figure 3). This general behavior was altered somewhat due to the operational issues that resulted in several extended periods during which the heating was turned off. A complete analysis of the resulting data is beyond the scope of this ITR, but a few key observations are provided below. Importantly, after reaching a peak removal near $165 \mathrm{lbs} /$ day (approximately 140 $\mathrm{lbs} /$ day in the East and $25 \mathrm{lbs} /$ day in the SW) the mass removal rate declined and stabilized near $10 \mathrm{lbs} / \mathrm{day}$. At the operating vapor flow rates, the current vapor concentrations are relatively low compared to peak values. Note that the extracted vapor concentration is a function of TCE removal rate divided by vapor flow rate (and is influenced by specific wells pumped and pulsing). In many cases, large increases in vapor flow rate result in relatively modest increases in mass flux (thus vapor concentration decreases as flow rate increases). As a result, the linkage of the extracted vapor concentration to remediation progress is somewhat indirect. Consistent with the 2007 ITR, we believe that mass removal is a more robust metric and recommend its use for assessing progress and "asymptosis."

Another important indicator of performance for the RGA is the impact of remedial system operation on groundwater concentration data. Interpretation of the RGA groundwater data within the treatment zone is complicated by the fact that water is continuously removed at a relatively low flow rate, treated to remove TCE and other contaminants, and then added back in (serving as a limited pump and treat in the high flow high permeability zone). As a result, the contaminant concentration in the RGA treatment zone groundwater would be expected to decrease over the course of an extended treatment operation. In general, this is what was observed. It is perhaps more interesting to follow the impact of the remediation on the downgradient groundwater. If contaminant is being effectively captured, then the downgradient concentrations would also be expected to decrease (after sufficient time for the signal to arrive at the monitoring location). The PGDP project team installed a number of monitoring wells that provide reasonable downgradient monitoring at several elevations within the RGA. While the period of monitoring is insufficient to develop a definitive conclusion, available data from some of the dowgradient wells (Figure 4) provide some initial indications of RGA treatment performance. 

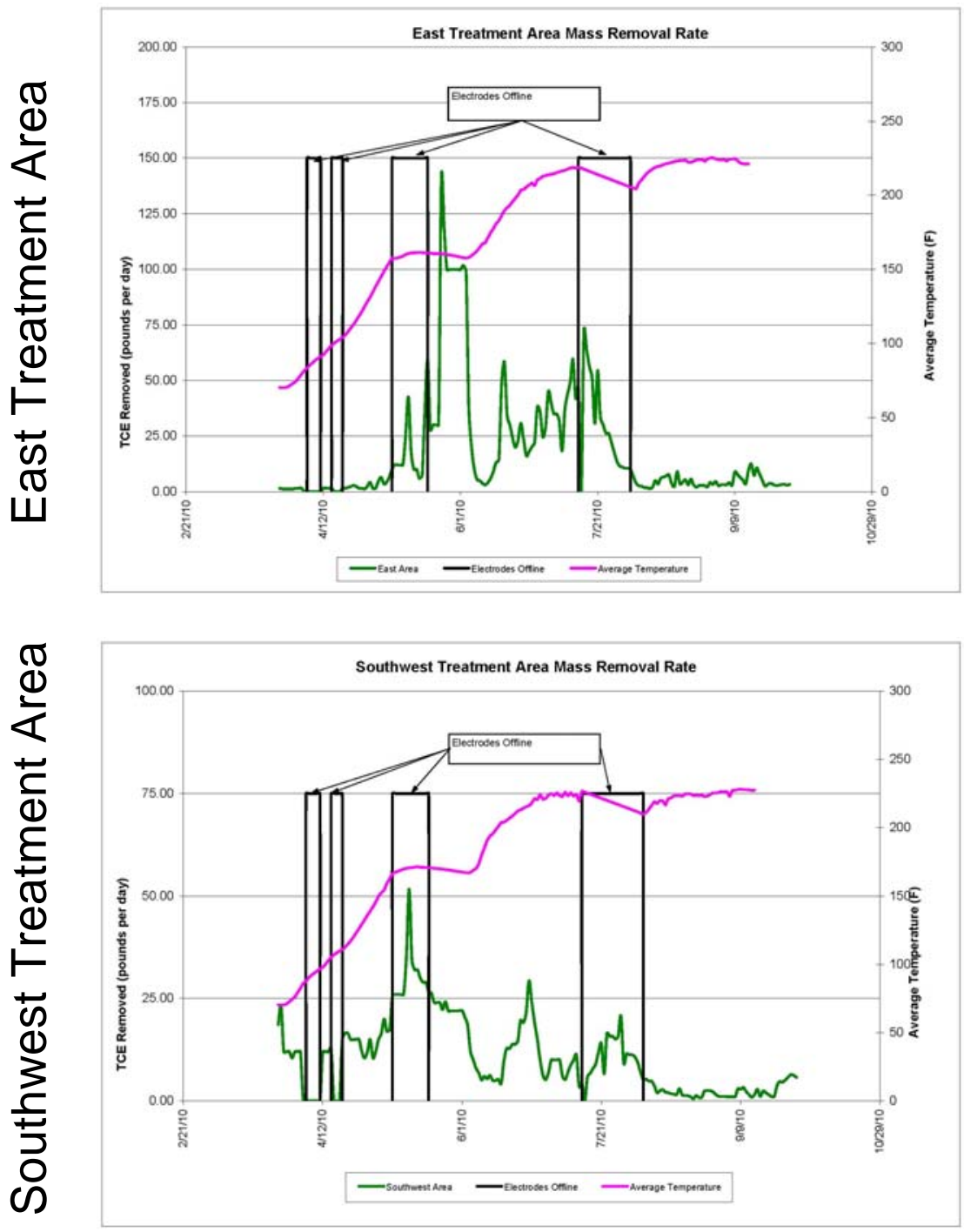

Figure 3. Mass removal rate (lbs/day) during Phase I of the C-400 ERH Treatment (these graphs also indicate average temperature and when the electrodes were offline) 


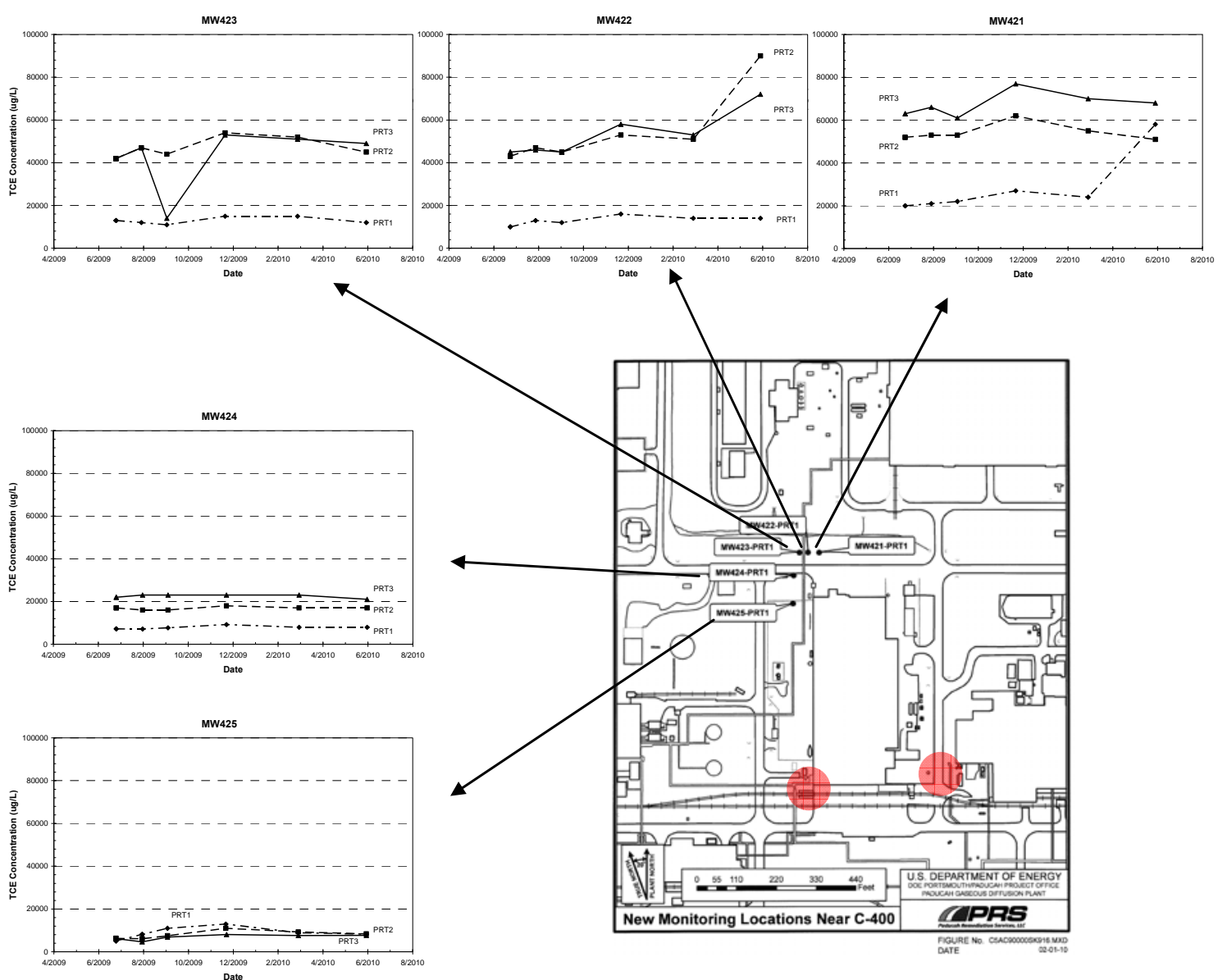

Figure 4. Response of downgradient RGA wells to Phase I ERH operation. The Phase I heating locations are marked in red and the data for TCE concentration as a function of time are shown for each elevation in each well.

Groundwater would be expected to flow from the heated areas toward monitoring well locations 421-425. Each of these wells is completed as a cluster with PRT1 installed in the upper RGA and PRT2 and PRT3 installed progressively deeper in the aquifer. Based on the elevated concentrations prior to heating, Figure 4 suggests that MW421, MW422 and MW 423 are strongly impacted by the C-400 Building TCE source zones while MW424 and MW 425 exhibit somewhat lower concentrations. The most notable early observations following Phase I heating are: a) the deepest screen zones in MW422 appear to be increasing and $b$ ) the shallowest screen in MW 421 appears to be increasing. These data may indicate measurable TCE migration (MW422) and/or vertical blending of the upgradient TCE source in the RGA during thermal treatment (e.g., MW 421). Based on the measurements of groundwater trends within the treatment zone, concentrations in down gradient wells might be expected to reverse and trend downward at some point in the near future. The ITR recommends continued evaluation of the response of these and 
other downgradient wells as important indicators of the performance of the thermal remediation toward the important-overarching ROD goals "to remove a significant portion of the VOCs from the subsurface in the vicinity of the C-400 Cleaning Building .... and to reduce the period of time that TCE contaminates groundwater."

\section{Project Implementation}

Design and Detailed Response to Earlier Recommendations -

An annotated synopsis of the 2007 ITR (Looney et al, 2007) issues and recommendations is provided in Appendix C. Notably, the PGDP team implemented some of the most important recommendations (e.g., a phased approach for the C-400 cleanup activities) but did not implement the bulk of the recommendations including many of the recommendations that were highlighted as "critical" to resolve prior to moving forward with the ERH heating technology. In particular, modeling and simulation issues and recommendations were not addressed and a significant number of the performance metric, characterization and design recommendations were either "not done" or "partially done." The PGDP team did consider and develop a specific written response to all of the 2007 ITR issues and recommendations, however, and implemented the project in a disciplined and careful manner working through a series of approved deliverables (RAWP, RDR, O\&M Plan, etc.). The following discussion documents the general observations that were developed during the current ITR site visit. As with the other portions of the report, this is not a comprehensive audit, but is intended to provide the PGDP team with useful input that will assist in planning and implementing future remedial activities at this site.

Overarching Technical Observations from Site Walkdown -

Overall, The C-400 thermal remediation site was impressive. The area was neat and well organized, and all employees were aware of the importance of safety and working in a complex multi-use environment. The Phase I ERH effort involved mobilization and operation of a large amount of equipment, training and management of a knowledgeable workforce, and coordination among multiple organizations and agencies.

In interviewing site personnel throughout the visit, the theme of "I am doing it this way because I was told to" was repeated many times. In follow up questions (e.g., "have you thought about ways to improve this," "has this worked for you," "did ... cause you some problems," "have you informed your manager about what you are seeing," etc.), the respondents typically did not have any additional response. The ITR believes that careful adherence to plans and procedures is necessary, particularly for large and complex projects, but that each employee must "own" their job, continuously exhibit thoughtful curiosity, and constantly strive to improve operations and efficiencies. The ITR encourages the PGDP team to encourage and increase their emphasis on an "ownership society" for future phases of the remediation. We believe that disciplined operations, controlled by reasonable procedures, can be developed in such a manner that they encourage, and are responsive to, creativity and insights of employees at all levels. 
Sampling - Observations from Site Walkdown -

The Innova model 1312 photoacoustic multigas analyzer is a good choice for monitoring compounds in the gas or vapor phase at the site. The optically filtered IR based system is consistent and accurate over a two to three order dynamic range (set by initial calibration) and can maintain its calibration for months to years with little intervention or need for recalibration. One of the most useful aspects of the instrument for monitoring soil gas is its ability to measure carbon dioxide concurrently with the volatile compound of interest (in this case TCE). Soil gas almost always contains carbon dioxide at a significantly higher concentration (1,000 ppmv to $20,000 \mathrm{ppmv}$ ) than surface air (400 to $500 \mathrm{ppmv}$ ). If carbon dioxide measurements are lower than average values found in the subsurface at a site it is usually an indication that ambient air is leaking into the sampling and analysis train and therefore diluting the concentration of the target compound. Soil gas measurements using an IR multigas monitor should generally include measurements of carbon dioxide concurrent with the target contaminant.

A pitfall of measuring soil gas is condensing water vapor. Although the 1312 uses a measurement cell that is heated above ambient temperatures, liquid water in the cell will interfere with accurate measurement results. In addition, condensed water in the sampling line can occlude the flow of soil gas making concentration measurements inconsistent. Often these issues can be recognized by inconsistent carbon dioxide measurements. Although site personnel have made efforts to reduce the likelihood of condensed water from soil gas affecting measurements, on several occasions they have had to "dry out" the instrument after a day of measurements because liquid water was sucked into the measurement cell. In addition, during their approximate 11 minute measurement interval at a particular well, they often encounter measurement values that differ by two orders of magnitude. This difference is unlikely to indicate actual differences in soil gas over this brief interval and is more likely due to sampling issues. Concurrent carbon dioxide measurements would help to determine if the large change in contaminant concentration represents actual subsurface conditions or is due to sampling problems. The model 1312 instruments are currently configured to analyze a few unnecessary parameters. At a minimum 1,1 DCE analysis should be discontinued and carbon dioxide substituted. This should help reduce uncertainties and discrepancies in soil gas measurements and may also indicate more general characteristics of the treatment system, for example, a consistent low carbon dioxide measurement that increases with depth (in comparison with other areas on site) may indicate the extent to which the soil vapor extraction system is pulling in surface air.

It is not clear why the highest frequency measurements are being collected from the least dynamic portion of the system (post treatment gas in which all measurements would be expected to be below detection and any changes would occur gradually). These measurements are being made at the expense of the most dynamic portion of the system (extraction wells). The ITR recommends that measurements of the post treatment gas be reduced to two times per day at maximum while pretreatment gas measurements should be more frequently to provide actionable information about system operations. Further, the concentration data collected for both vapor and water phases at all sampled locations, 
and key parameters associated with the vapor and liquid treatment system operations should be made available/accessible using a database system similar to the Phase I web portal (this portal provided access to heating and power information).

Water Treatment System - Observations from Site Walkdown -

The vapor and liquid treatment systems and controls consisted of a variety of unit operations that were combined into a treatment system to address the expected waste stream. In general the system was appropriate for the challenges of a complex feedstream typical of thermal remediation. The team noted, however that significant unit operations within this system were leased or rented and that this arrangement is not consistent with a source zone thermal treatment in which the treatment of vapor and liquid should extend well beyond the operation period of the heating (this topic was strongly emphasized in the 2007 ITR report and the inclusion of leased/rented equipment should have been recognized as a decision that would sharply increase costs). One of the categories of leased equipment was the cryogenic condensation treatment units according to site personnel, these systems have been difficult to operate and they are not adequately integrated into the treatment system process controls. Based on these statements, and the lower TCE inventory estimates discussed above, the ITR recommends discontinuing the leasing of this equipment and making appropriate design modifications to allow continued treatment operations. Similarly, the ITR recommends removal of other unit operations that are in place to treat contaminants that have not been measured in substantive quantities (e.g., vinyl chloride), particularly those that are incurring charges. Leased/rented equipment that is essential to operations (e.g., surge tanks) should be replaced or purchased if a cost evaluation (assuming several years of operation) indicates that the purchase would reduce lifecycle cost.

The following specific operating concerns were identified during the walkdown. These are provided to assist the PGDP as they plan for Phase II cleanup activities. While this is not a comprehensive list, the ITR is providing these observations to help assure that the design for future activities meets standard and peak operating needs.

o The cryogenic condensation and recovery units are independent systems and are difficult to integrate into the process resulting in operating difficulties. The performance of these systems suggests that designers should use caution in selecting and using a large number of small system packages in parallel operation to meet relatively high system flow requirements.

o The original (as designed) un-insulated vapor piping system pipelines allowed condensate formation without adequate provision for condensate removal. Modifications to the system alleviated the problems after several operating issues were encountered, particularly during cold weather operations. This issue contributed to extended periods of no subsurface heating and longer times to reach subsurface temperature goals in the UCRS.

o The initial ERH project was implemented using a sole source to a thermal remediation contractor based on a patented process called ET-DSPTM that uses a proprietary electrode design that was intended to provide unique capabilities to 
heat in the heterogeneous and challenging subsurface conditions in the vicinity of C-400. The results and lessons-learned from Phase I do not support these claims. As a result, the current ITR recommends that ERH activities for Phase II be awarded based on a best value competitive bid. A secondary benefit of this course of action is that the electrode spacing and power requirements are significantly less stringent for the UCRS, reducing the thermal remediation costs and allowing resources to be preserved to allow alternative technology to be deployed in the RGA.

o Critical data to support performance assessment, such as individual well flowrates and concentrations, are not available during most of the treatment. A header vapor flowrate meter for the East Area combined with the SW Treatment areas was added to the recorded data within the last month of operation. Prior to this only total vapor flowrates were measured just downstream of the air stripper.

o Phase I operational problems have resulted from both mineral precipitation and particulate solids. For example, iron and manganese are present in the RGA groundwater at C-400. Any iron or manganese that is extracted in a dissolved "reduced" state is subject to oxidation in various locations within the treatment system (e.g., the air stripper), forming solid hydroxides/oxides. Designs to avoid and mitigate the resulting plugging in the air stripper and process piping are recommended to avoid performance reduction. The ITR also noted potential problems associated with the screen sizes in some of the RGA pumping/extraction wells that might allow solids to interfere with pump operation and reduce extraction rates and hydraulic control.

o The Pulsed Operation Plan was prepared by $\mathrm{Mc}^{2}$; however, in our teleconference (9-15-10), $\mathrm{Mc}^{2}$ had not reviewed recent measured concentrations of extracted vapors and liquids. Hence, the basis for the pulsed operation was not clear. The plan at the East site was to extract from two of four wells for three days and then switch extraction to the other two wells for three days. At the end of this period, the two initial extraction wells would be opened to extraction for at least two hours and then all four wells would be sampled. More meaningful sampling would be daily concentrations from the operating extraction wells for each of the six days. The plan then specifies extracting from the two wells yielding the highest concentrations. This is better termed as the two wells producing the highest mass extraction rates. This extraction period is followed by extraction in all four wells at a very low extraction rate for four days and then four days at maximum extraction rates. The plan calls for concentration measurements at the end of the maximum flow period. It is recommended that daily measures of concentration from all wells be collected to assess the changes in concentration resulting from the changes in subsurface flow. Justifications for the durations of extraction in varying configurations are not provided. A description of the methods of data interpretation relating the results to remedial objectives is not provided; hence the basis for the pulsed operation is suspect. Similar concerns and recommendations (i.e., measure vapor concentrations in extraction wells daily) apply to the pulsed operation plan for the southwest area. The plans for determining performance vis-à-vis monitoring data, particularly related to shut off criteria should be more carefully and technically developed for Phase II. 
The ITR urges the PGDP to implement modifications to the vapor and liquid system carefully in a manner that will support mass removal in the period between Phase I and Phase II and in a manner that will support more efficient and effective operations during Phase II.

\section{$\underline{\text { Costs and project structure }}$}

The Phase I costs were approximately $\$ 32.5$ million; approximately $\$ 13$ million associated with construction and approximately $\$ 19.5$ million associated with operations (Phase I had a complex operating structure/organization. PRS/ LATA was the project manager, Shaw was the process operator on the surface, Mc2 was the subsurface project operator and other organization provided specific categories of logistical support. The operations costs include all of the various organizations). Notably, the Phase I costs significantly exceed the costs provided to the 2007 ITR and are higher than the costs estimated in the RDR. Importantly, based on the previous (lower) cost estimates, the overarching recommendation from the 2007 ITR was:

The ITR team determined that the estimated cost for ERH thermal treatment at the $C-400$ Building is within the range of thermal treatment costs at other federal sites on a per treatment volume and per electrode basis. Nonetheless, the cost is near the upper end of the historical range and further cost refinement and cost reduction opportunities should be pursued as the project plans are finalized. (Looney et al., 2007)

Based on the higher actual realized costs, the current ITR believes that the PGDP team did not adequately focus on cost refinement and cost reduction opportunities. This is exemplified by the Phase I unitized costs. If we generously assume that about half of the construction costs can be assigned to Phase II (since much of the vapor and water infrastructure is planned for follow-on use), then the adjusted Phase I costs are approximately $\$ 25$ million ( $\$ 13$ million construction $-\$ 7.5$ million construction allocated to Phase II $+\$ 19.5$ million operations). The sum of the treatment volume in the Phase I treatment areas (SW and E) was approximately 10,000 cu yd. Thus, the realized unit costs for the PGDP C-400 thermal treatment Phase I were approximately $\$ 2,500$ per $\mathrm{cu}$ yd and these unit costs substantially exceed the range of previous thermal treatment costs (e.g., $\$ 100$ to $\$ 1,020$ per cu yd with a median of approximately $\$ 200$ per cu yd; see Looney et al., 2007 and Baker, 2006); the phase I unit costs are 2.5x higher than the highest previously documented full scale thermal remediation unit costs. Based on the experience of the current ITR these are the highest unit costs for full scale remediation ever realized. Such high costs suggest a lack of focus on important project management controls and the need for a renewed commitment to cost effectiveness as the site moves into future phases of clean-up. 
The ITR generated a preliminary list of cost related observations to assist the PGDP team as they plan for Phase II:

o Costs to date do not include waste disposition or ongoing costs while PGDP works with regulators to develop a path forward. It is unclear if power costs have been included in the costs that were provided to the current ITR; based on the energy applied to the electrodes, the power costs for the Phase I effort are approximately $\$ 0.75$ million.

o Some of the high operating costs were related to the high indirect costs for escorts, foreign national security, long term housing and living costs for temporary duty (TDY) staff, transportation, etc. These and other costs should be avoided by the use of full time, cleared staff from local sources.

o In some cases, the project infrastructure, while impressive, was outside of industry norms in terms of expenditures. A specific example is that redundant state of the art touch screen process control panels were installed for the water treatment process - one in the main equipment enclosure and a second (slave controller) in the adjacent personnel trailer. While this was presented as necessary for safety (to minimize potential danger from lightning strikes), the ITR was not convinced that walking the few feet between the trailer and the equipment enclosure was a significant risk that justified the expenditure of 10s of thousands of dollars. The ITR recommends that Phase II be held to a high standard of safety but that decisions should be based on a more industry standard graded approach that implements systems in a fiscally disciplined frugal manner that safely achieves functional goals.

o A significant contributor to the high costs was the decision to lease or rent significant unit operations within the vapor/water treatment system. The process equipment which has been obtained through continuing leasing agreements has generated project lifecycle costs that far exceed the cost that would have been realized by purchasing the equipment. Replacement and warranty issues are also an operating financial concern.

$\underline{\text { Lessons learned for Phase II }}$

The current ITR assessment of performance and lessons learned are summarized in the various topical sections above. During the September, 2010 ITR visit, the PGDP site contractor (currently LATA) was receptive to alternative designs for Phase II operations. Currently, LATA is exploring a design option generated by the Phase I ERH contractor for the UCRS. Other remediation technologies are being evaluated for treatment of the TCE source in the RGA..

In general, the $\mathrm{MC}^{2}$ assessment and lessons learned from Phase I were that the RGA permeability/flow were higher than assumed in their Phase I models and that significantly more power, more electrodes, and interception of upgradient water are needed to improve performance. They note that at very high flow rates (e.g., 6 feet per day), even this "full throttle" approach may not meet the heating objectives. Note that all of the $\mathrm{MC}^{2}$ conclusions from Phase I and plans for Phase II are based entirely on numerical models which have proven to be inaccurate at this site and which are based on suspect and fragile boundary conditions. Further, these models have not been validated for the RGA in the 
vicinity of the C-400 Building despite the fact that the entire Phase I database of site configuration, power applied, heating and extraction were available to the contractor. In lieu of this obvious and technically robust approach, a simplistic and flawed analysis of groundwater flow was performed (this calculation serves as a primary basis for assuming that the water flow rates are viable for a beefed up phase II concept).

According to $\mathrm{Mc}^{2}$, a simple mathematical approach was used, with a snapshot of data from Phase I, to estimate the groundwater flow velocity within the deep RGA by matching actual temperature data from D007 (as a pulse of heat moved through the system). Note that the following discussion references the Phase I monitoring locations and graphs that were provided by $\mathrm{Mc}^{2}$ for a modeling-based Phase II conceptual design report. In the modeling, groundwater flow velocity was estimated to range between 1.82 and 3.04 feet per day. The write-up does not describe how the initial temperature distribution was determined (depicted in the Phase II concept report Figure 2.2). Electrode E012 is almost directly upgradient of D007 used for the temperature modeling and is assumed to be at $\sim 25 \mathrm{C}$ for the simulation. Hence, the calculation is not valid as the initial condition has no basis. In addition, temperature at the nearby D005 dropped precipitously at $84.6 \mathrm{ft}$ bgs after the power outage. These observations suggest the groundwater velocity could be significantly higher than $3 \mathrm{ft} /$ day and the interpretation is invalid. According $\mathrm{Mc}^{2}$, the RGA can not be treated by ET-DSPTM (the variant of ERH used in Phase I) if the groundwater velocity is greater than about $6 \mathrm{ft} /$ day. The ITR believes that the simple flow calculation is not useful, that the groundwater velocity may be higher than $3 \mathrm{ft} / \mathrm{day}$, and that $\mathrm{Mc}^{2}$ should have concluded that there is a potential that ERH is not viable for the RGA, even if implemented aggressively.

The $\mathrm{Mc}^{2}$ design option is likely to result in a substantial increase in the cost for the phase II construction (originally estimated to be approximately $\$ 10$ million). The current ITR believes that the available data suggest a significant risk of underperformance, even with the new design. The extreme efforts being proposed to heat the RGA, a zone that Phase I demonstrated is poorly matched to the capabilities of ERH, are principal drivers in increasing project, costs, complexity and risk.

\subsection{Phase II}

ITR review of $\mathrm{Mc}^{2}$ proposal -

As noted above, the ITR assessment determined that Phase I results indicate that the UCRS and uppermost RGA were heated to the target temperature and the gas phase concentrations decreased over time and stabilized at relatively low concentrations (i.e., "asymptosis"). If confirmatory borings in the UCRS confirm significant TCE source reduction, then Phase I can be considered successful in achieving the regulatory/technical objectives in this zone. Conversely, the temperature goals were generally not achieved in the RGA (particularly in the deep RGA) during Phase I, substantially validating the concerns expressed in the earlier (Looney et al., 2007) independent review. The data confirm that in a high permeability - high flow aquifer, thermal remediation is inefficient with a significant proportion of the applied energy and/or complex engineering and operational efforts focused on minimizing heat loss and in distributing the energy 
throughout the target zone. These topics were specifically identified and discussed in detail in the earlier (2007) review and will not be repeated here.

In response to the earlier technical review, $\mathrm{Mc}^{2}$ and the project team expressed confidence in their ability to meet temperature objectives throughout the RGA - based on modeling and proprietary electrode and control systems. Actual performance during Phase I clearly document that previous modeling results were inaccurate and that the proprietary electrodes and control systems provide little, or no, unique capabilities in overcoming the challenges of high permeability and high flow in the RGA. In preparing for Phase II, the $\mathrm{Mc}^{2}$ approach was no different than their Phase I strategy in that they ran similar numerical models in a similar manner leading to a similar expression of confidence in their ability to achieve temperature goals throughout the RGA. The resulting Phase II planning was entirely modeling-based with no documentation or critical evaluation of Phase I field data, no exploration of alternative modeling approaches (i.e., utilizing more appropriate boundary conditions and comparison of results to simple analytical models of limiting cases for perspective), and minimal focus on the impacts of the proposed alterations on logistics and costs. The previous ITR team found the initial $\mathrm{Mc}^{2}$ modeling results unconvincing -- the current ITR team found the modeling to support Phase II unconvincing for the same general reasons. Importantly, in preparing for Phase II $\mathrm{Mc}^{2}$ had every opportunity to convincingly validate and calibrate their model based on the detailed energy, temperature and pressure dataset collected during Phase I but did not perform this obvious task. Thus, while the proposed Phase II engineering modifications may represent a plausible scenario, the ITR found the basis for the modifications to be wholly insufficient. Based on the Phase I results, the ITR team determined that ERH (or any of the other thermally enhanced removal technologies) is poorly matched to the RGA conditions in the vicinity of the C-400 building and recommends that heating technology be eliminated from Phase II for this particular zone. Instead, we recommend that the Paducah project team and their regulators and stakeholders, identify a technology that is better matched to the target zone - one that will lead to better performance, lower costs, reduced collateral impacts (e.g., energy use), reduced drilling, etc. These alternatives are described in more detail below.

ITR alternatives evaluation -

According to the available information, a substantial TCE source is present in both the UCRS and the RGA in the southeast treatment zone that is targeted in Phase II. The ITR recommendation to eliminate thermal remediation the Phase II RGA treatment zone does not imply that this contamination is not important. The ITR advocates treating this target contamination to achieve the ROD commitments and objectives, but using technologies that are better matched to the high flow and high permeability conditions. Moreover, based on the data from Phase I, ERH heating appeared to be relatively effective and efficient in the UCRS and the ITR recommends that deployment of ERH proceed for the UCRS in the southeast treatment zone. 
In transitioning from Phase I Phase II, the current ITR has the following more specific recommendations:

- Turn off heat (i.e., power to the Phase I electrodes) but continue recovery of vapor and groundwater to the extent practicable.

- Simplify treatment system based on actual concentrations and performance in Phase I - (e.g., use GAC as primary capture system and remove chillers, zeolite systems, etc. unless there is a compelling technical basis to the contrary) .

- Demobilize leased equipment wherever possible - if some of this equipment needs to be replaced, a procurement should be initiated.

- Consider opportunistic reagent addition to RGA in SW C400 if needed to supplement Phase I efforts (e.g., add oxidant to injection ports).

In identifying and implementing technologies the current ITR recommends: a) that the PGDP project team and their regulators and stakeholders, identify a technology that is better matched to the RGA target zone - one that will lead to better performance, lower costs, reduced collateral impacts (e.g., energy use), reduced drilling, etc., and 2) a culture that encourages all personnel to understand the overall goals of the remediation and their important roles in making the project a success - this type of "ownership society" is key to implementing a cost effective Phase II action. The ultimate success for remediation at this site will hinge on making the necessary "give and take" decisions and in implementing the resulting technology portfolio skillfully and efficiently.

The remainder of this section addresses the considerations related to defining an appropriate technology for the RGA. In general, the technology classes that should be considered include one or more of the following: pump-and-treat, chemical oxidation, cosolvent/surfactant extraction, and enhanced (reductive) bioremediation. For completeness we have included thermally enhanced remediation in the discussion. We have not included standard isolation/immobilization technologies (e.g., caps or walls) at this juncture because traditional implementations are unlikely to yield reasonable performance - note however that some technologies include isolation/immobilization features (e.g., partitioning into oils). In a general sense, technologies that benefit from the ability to inject and control liquid reagent in the subsurface and that have sufficient longevity to address back diffusion from the underlying McNairy Formation represent the best match for RGA conditions. This discussion presumes that aggressive thermal remediation of the UCRS (as planned for Phase II) will substantially reduce future discharge from the overlying formation into the RGA.

The matrix in Table 1 provides a qualitative discussion of some of the key factors related to potential RGA technologies. 
Table 1. RGA technology matrix for Phase II TCE treatment

\begin{tabular}{|c|c|c|c|}
\hline Technology Description & $\begin{array}{l}\text { Reagent injectability and } \\
\text { controllability }\end{array}$ & $\begin{array}{l}\text { Reagent longevity to address } \\
\text { McNairy }\end{array}$ & Summary \\
\hline \multicolumn{4}{|l|}{ Extraction Technology } \\
\hline $\begin{array}{l}\text { Pump and Treat in the RGA - } \\
\text { pump highly contaminated } \\
\text { groundwater from the RGA } \\
\text { Phase II RGA target zone } \\
\text { (e.g., beneath UCRS heating } \\
\text { zone) to an appropriately } \\
\text { modified treatment system }\end{array}$ & $\begin{array}{l}\text { Not applicable (no reagent), } \\
\text { however, based on Phase I data, } \\
\text { pump and treat is likely to } \\
\text { remove TCE from the RGA } \\
\text { more effectively than the } \\
\text { planned heating system }\end{array}$ & $\begin{array}{l}\text { Does not specifically remove or } \\
\text { destroy McNairy contamination } \\
\text { and does not provide post } \\
\text { operational capability to address } \\
\text { back diffusion from the McNairy }\end{array}$ & $\begin{array}{l}\text { Recommended as a prudent } \\
\text { action between Phase I and } \\
\text { Phase II. Recommended as a } \\
\text { Phase II action during UCRS } \\
\text { Heating } \\
\text { May be useful as a bulk } \\
\text { removal activity prior to } \\
\text { reagent injection. }\end{array}$ \\
\hline \multicolumn{4}{|l|}{ Oxidant } \\
\hline $\begin{array}{l}\text { Permanganate Solution - } \\
\text { Inject potassium or sodium } \\
\text { permanganate solution in SE } \\
\text { RGA target volume }\end{array}$ & $\begin{array}{l}\text { Reagent is well suited to } \\
\text { injection and relatively safe. } \\
\text { High strength (dense) solutions } \\
\text { can be deployed at the McNairy } \\
\text { interface. Permanganate results } \\
\text { in pink/purple water. }\end{array}$ & $\begin{array}{l}\text { Some diffusive penetration into } \\
\text { the McNairy is expected and } \\
\text { deployment at the interface will } \\
\text { provide limited sustainability } \\
\text { (e.g., months to years). High } \\
\text { RGA groundwater flow would } \\
\text { flush reagent from site after } \\
\text { deployment reducing longevity. }\end{array}$ & Potentially viable for RGA. \\
\hline
\end{tabular}


Table 1. RGA technology matrix for Phase II TCE treatment (continued)

\begin{tabular}{|c|c|c|c|}
\hline Technology Description & $\begin{array}{c}\text { Reagent injectability and } \\
\text { controllability }\end{array}$ & $\begin{array}{c}\text { Reagent longevity to address } \\
\text { McNairy }\end{array}$ & Summary \\
\hline \multicolumn{4}{|c|}{ Oxidant Technology (continued) } \\
\hline $\begin{array}{l}\text { Persulfate Solution - Inject } \\
\text { persulfate solution in SE RGA } \\
\text { target volume }\end{array}$ & $\begin{array}{l}\text { Reagent is well suited to } \\
\text { injection and relatively safe. } \\
\text { High strength (dense) solutions } \\
\text { can be deployed at the McNairy } \\
\text { interface. May require } \\
\text { activation to achieve desired } \\
\text { performance. }\end{array}$ & $\begin{array}{l}\text { Some diffusive penetration into } \\
\text { the McNairy is expected and } \\
\text { deployment at the interface will } \\
\text { provide limited sustainability } \\
\text { (e.g., months to years). High } \\
\text { RGA groundwater flow would } \\
\text { flush reagent from site after } \\
\text { deployment reducing longevity. }\end{array}$ & Potentially Viable for RGA \\
\hline $\begin{array}{l}\text { Peroxide Solution - Inject } \\
\text { peroxide solution in SE RGA } \\
\text { target volume (along with } \\
\text { activation adjunct) }\end{array}$ & $\begin{array}{l}\text { Reagent is well suited to } \\
\text { injection and effective in } \\
\text { degrading TCE, but generates } \\
\text { large volumes of gas. Difficult } \\
\text { to deploy at the McNairy } \\
\text { Interface. }\end{array}$ & $\begin{array}{l}\text { Peroxide decays rapidly and this } \\
\text { chemistry would provide limited } \\
\text { penetration into the McNairy and } \\
\text { no significant sustainability. }\end{array}$ & $\begin{array}{l}\text { Not recommended for the } \\
\text { RGA }\end{array}$ \\
\hline $\begin{array}{l}\text { Soil blending - blend in } \\
\text { permanganate solid from the } \\
\text { surface (this would treat both } \\
\text { the UCRS and RGA) }\end{array}$ & $\begin{array}{l}\text { Not applicable (viable) at this } \\
\text { site because of depth, cultural } \\
\text { interferences, safety concerns, } \\
\text { etc. }\end{array}$ & Not viable & $\begin{array}{l}\text { Not viable. Poor match to } \\
\text { the RGA in the vicinity of } \\
\text { the C- } 400 \text { building. }\end{array}$ \\
\hline
\end{tabular}


Table 1. RGA technology matrix for Phase II TCE treatment (continued)

\begin{tabular}{|c|c|c|c|}
\hline Technology Description & $\begin{array}{l}\text { Reagent injectability and } \\
\text { controllability }\end{array}$ & $\begin{array}{l}\text { Reagent longevity to address } \\
\text { McNairy }\end{array}$ & Summary \\
\hline \multicolumn{4}{|c|}{ Enhanced Extraction Using Liquid Solutions } \\
\hline $\begin{array}{l}\text { Cosolvent Solution - Inject } \\
\text { cosolvent solution (e.g., high } \\
\text { molecular weight alcohol) to } \\
\text { mobilize residual DNAPL for } \\
\text { collection }\end{array}$ & $\begin{array}{l}\text { Reagent is well suited to } \\
\text { injection and might result in a } \\
\text { secondary process of transient } \\
\text { biological degradation of TCE in } \\
\text { anaerobic pockets generated as a } \\
\text { result of degradation of residual } \\
\text { cosolvent in the formation. } \\
\text { Mobilization requires effective } \\
\text { capture a has an increased } \\
\text { technical risk compared to in situ } \\
\text { destruction. }\end{array}$ & $\begin{array}{l}\text { Does not specifically remove or } \\
\text { destroy McNairy contamination } \\
\text { and does not explicitly provide } \\
\text { post operational capability to } \\
\text { address back diffusion from the } \\
\text { McNairy (except for fortuitous } \\
\text { anaerobic degradation) }\end{array}$ & $\begin{array}{l}\text { Potentially viable, but entails } \\
\text { has more uncertainty and } \\
\text { more technical risk than in } \\
\text { situ destruction. }\end{array}$ \\
\hline $\begin{array}{l}\text { Surfactant Solution - Inject } \\
\text { surfactant solution to form } \\
\text { microemulsions that mobilize } \\
\text { residual DNAPL for } \\
\text { collection }\end{array}$ & $\begin{array}{l}\text { Reagent is well suited to } \\
\text { injection. Similar } \\
\text { advantages/disadvantages to } \\
\text { cosolvent but may have higher } \\
\text { cost and less potential for } \\
\text { secondary biodegradation. }\end{array}$ & Similar to cosolvent & $\begin{array}{l}\text { Potentially viable, but entails } \\
\text { has more uncertainty and } \\
\text { more technical risk than in } \\
\text { situ destruction. }\end{array}$ \\
\hline
\end{tabular}


Table 1. RGA technology matrix for Phase II TCE treatment (continued)

\begin{tabular}{|c|c|c|c|}
\hline Technology Description & $\begin{array}{c}\text { Reagent injectability and } \\
\text { controllability }\end{array}$ & $\begin{array}{l}\text { Reagent longevity to address } \\
\text { McNairy }\end{array}$ & Summary \\
\hline \multicolumn{4}{|c|}{ Enhanced (Reductive) Bioremediation } \\
\hline $\begin{array}{l}\text { Emulsified and liquid } \\
\text { vegetable oil solutions/liquids } \\
\text { - Inject emulsified and liquid } \\
\text { oil solutions to generate } \\
\text { reductive conditions that } \\
\text { encourage destruction. May } \\
\text { require supplemental micro- } \\
\text { organism addition as well. }\end{array}$ & $\begin{array}{l}\text { Emulsified oil reagent is suited } \\
\text { to injection but is less mobile } \\
\text { than carbohydrate substrates } \\
\text { such as molasses (potentially } \\
\text { requiring more wells). Reliably } \\
\text { generating anaerobic conditions } \\
\text { throughout the RGA would } \\
\text { require large amounts of } \\
\text { amendment and the high flow } \\
\text { rate would flush reagent from } \\
\text { the treatment zone relatively } \\
\text { rapidly. At this site, emulsified } \\
\text { oil could be supplemented with } \\
\text { liquid (neat) vegetable oil that } \\
\text { would float to the UCRS/RGA } \\
\text { interface and provide a } \\
\text { partitioning and bioreaction zone } \\
\text { at that location. }\end{array}$ & $\begin{array}{l}\text { Little diffusive penetration into } \\
\text { the McNairy is expected. } \\
\text { Because of reagent flushing and } \\
\text { the influx of electron acceptors } \\
\text { (oxygen, etc.) from upgradient, } \\
\text { this process is not expected to } \\
\text { provide limited sustainability } \\
\text { (e.g., months). }\end{array}$ & $\begin{array}{l}\text { Potentially viable, but entails } \\
\text { has more uncertainty and } \\
\text { more technical risk than in } \\
\text { situ destruction. }\end{array}$ \\
\hline
\end{tabular}


Table 1. RGA technology matrix for Phase II TCE treatment (continued)

\begin{tabular}{|c|c|c|c|}
\hline Technology Description & $\begin{array}{c}\text { Reagent injectability and } \\
\text { controllability }\end{array}$ & $\begin{array}{l}\text { Reagent longevity to address } \\
\text { McNairy }\end{array}$ & Summary \\
\hline \multicolumn{4}{|c|}{ Enhanced (Reductive) Bioremediation (continued) } \\
\hline $\begin{array}{l}\text { Carbohydrate } \\
\text { solutions/liquids - Inject } \\
\text { carbohydrate (e.g., molasses, } \\
\text { or ethyl lactate) solutions to } \\
\text { generate reductive conditions } \\
\text { that encourage destruction. } \\
\text { May require supplemental } \\
\text { micro-organism addition as } \\
\text { well. }\end{array}$ & $\begin{array}{l}\text { Most carbohydrate reagent is } \\
\text { well suited to injection. Reliably } \\
\text { generating anaerobic conditions } \\
\text { throughout the RGA would } \\
\text { require large amounts of } \\
\text { amendment and the high flow } \\
\text { rate would flush reagent from } \\
\text { the treatment zone relatively } \\
\text { rapidly. }\end{array}$ & $\begin{array}{l}\text { Little diffusive penetration into } \\
\text { the McNairy is expected. } \\
\text { Because of rapid reagent } \\
\text { flushing, the influx of electron } \\
\text { acceptors (oxygen, etc.), and the } \\
\text { labile nature of carbohydrate } \\
\text { substrates, this process is } \\
\text { expected to provide minimal } \\
\text { sustainability (e.g., weeks to } \\
\text { months). Requirement for } \\
\text { frequent and multiple injections } \\
\text { would be probable. }\end{array}$ & $\begin{array}{l}\text { Potentially viable, but entails } \\
\text { has more uncertainty and } \\
\text { more technical risk than in } \\
\text { situ destruction. The need } \\
\text { for frequent reinjections } \\
\text { makes this technology } \\
\text { somewhat analogous to } \\
\text { pump and treat in its } \\
\text { operations and maintenance } \\
\text { profile. }\end{array}$ \\
\hline \multicolumn{4}{|c|}{ Thermally Enhanced Extraction } \\
\hline Electrical Resistance Heating & $\begin{array}{l}\text { Poorly matched to RGA } \\
\text { conditions based on Phase I } \\
\text { performance. }\end{array}$ & $\begin{array}{l}\text { Poorly matched to RGA } \\
\text { conditions. }\end{array}$ & $\begin{array}{l}\text { Has not demonstrated } \\
\text { viability for these conditions }\end{array}$ \\
\hline Steam Flood & $\begin{array}{l}\text { This technology is subject to the } \\
\text { same fundamental limitations as } \\
\text { ERH. Poorly matched to RGA } \\
\text { conditions }\end{array}$ & $\begin{array}{l}\text { Poorly matched to RGA } \\
\text { conditions. }\end{array}$ & $\begin{array}{l}\text { Has not demonstrated } \\
\text { viability for these conditions }\end{array}$ \\
\hline
\end{tabular}


The most promising potential alternatives to remediate TCE contamination in the RGA are the application of oxidant solutions or the application of amendments to enhance biological degradation (reduction). Simple extraction, using pump and treat is also relatively effective in the high flow RGA conditions. Relatively high ORP and dissolved oxygen values in the RGA suggest oxidation as the most appropriate aggressive remediation option but the presence of TCE mass in fine grain zones out of the advective flow path may provide opportunities for enhanced reductive dechlorination. Due to the depth and thickness of the RGA, there are limited options for emplacement and distribution of the amendments. Injection through temporary (e.g., Geoprobe) or permanent (e.g., through wells) points at multiple depths will probably provide the best opportunity for distribution of the amendment.

\section{Oxidation}

There are several oxidants that have effectively remediated TCE in situ including hydrogen peroxide, permanganate, and persulfate, and each have advantages and disadvantages with respect to application at this site. Hydrogen peroxide based methods such as Fenton's reagent have fast kinetic rates which is appropriate for the limited contact time expected in the fast-flowing RGA. Unfortunately, Fenton's reagent also creates a great deal of gas and heat which tends to displace contaminant-laden fluids and limit contact of the oxidant with TCE.

Sodium persulfate is a strong oxidant which is effective on TCE but has slower oxidation rates which may limit its effectiveness on residual TCE in the RGA. Persulfate's kinetic rate is dramatically enhanced with increasing temperature, though and may be much more effective if the RGA is at $40 \mathrm{deg} \mathrm{C}$ rather than 15 or 20 degrees $\mathrm{C}$. Based on rapidly changing temperature data from the RGA during periods when the electrodes were turned on or off, persulfate would have to be applied soon after heating has ended to take advantage of the short-lived increased temperature in the RGA. A potential disadvantage of the application of persulfate is that sulfate is created when persulfate is consumed in oxidation. Although most of it will be flushed out of the system, remaining sulfate accumulating in low flow zones may impede subsequent reductive dechlorination in the aquifer by acting as a competing electron acceptor when ORP is low enough to promote sulfate reduction.

Permanganate (either sodium or potassium) may be the most appropriate oxidant for this site. Permanganate's reaction rates are relatively fast and permanganate has been successfully used to remediate many TCE contaminated sites. The most critical component in the application of permanganate (or any amendment) is satisfactory distribution. The RGA is wrought with pathways of variable permeability. The permeability contrasts determine where most of the fluid in the system will travel. For effective treatment, it will be imperative for the amendment to be distributed both in the fastest flowing paths and the slowest flowing paths (likely location of most of the residual contamination in the RGA). Injection of amendment at multiple depths (e.g., through direct push, or well clusters) may help provide adequate distribution. 


\section{Biological (and Enhanced Abiotic) Reduction}

If remaining TCE is trapped in fine grain pores well away from the advective flow paths, this residual source will feed the advective plume until the residual mass is depleted. Residual mass in fine grain pores may be in the RGA, above it in the UCRS, or below it in the McNairy. Despite high ORP values $(>200 \mathrm{mV})$ and dissolved oxygen $(>2 \mathrm{mg} / \mathrm{l})$, there is some evidence of reductive dechlorination of the TCE (small amounts of cis dichloroethene) which is presumably occurring in the fine grain zones out of the primary advective flow paths. Enhancing reductive dechlorination in these zones may be justified if a substantial amount of contaminant mass remains there. Accessing these zones with amendment is difficult and may only be effectively achieved by diffusion. As with oxidants, to achieve penetration into these zones by diffusion, the amendments must be persistent. If a substantial residual mass is held in fine zones in the McNairy, it may be possible to effectively apply a persistent reductive amendment. A dense organic carbon amendment to encourage bio reductive dechlorination and/or zero valent iron may be effectively distributed at the RGA/McNairy interface by injection. This type of amendment may persist for months to years and will control flux of TCE from the McNairy into the RGA. Applying a reductive amendment in either the RGA or the UCRS will be more difficult but may be considered after an oxidant injection.

\section{Pump and Treat Extraction in the Source Area}

As a scoping calculation for aqueous phase pump and treat: extracting from the Phase I RGA at $5 \mathrm{mg} / 1$ and $40 \mathrm{gpm}$ is equivalent to approximately $1.1 \mathrm{~kg}(\sim 2.5 \mathrm{lbs})$ of TCE recovered from the aqueous phase per day. If a well in the southeast (Phase II treatment zone) were added at $40 \mathrm{gpm}$ and average aqueous concentration of $150 \mathrm{mg} / \mathrm{l}$, an additional $32.8 \mathrm{~kg}$ ( $\sim 72 \mathrm{lbs})$ per day of TCE would be recovered. 


\section{References}

Baker, R., 2006. In situ remediation of soil contaminated with organic contaminants. Presented at, Prevention and Remediation in Selected Industrial Sectors: Small Sites in Urban Areas, Athens, Greece, June 2006, NATO/CCMS Pilot Study (available at: http://www.clu-in.org/athens/download/Organic Contaminants/US-Ralph_Baker.pdf )

Butherus, M., Ingle, D.S., Juhlin, R., and Daniel, J. Project Overview: Successful FieldScale In Situ Thermal NAPL Remediation. Paper presented at the Third International Conference on Oxidation and Reduction Technologies for Soil and Groundwater, San Diego, CA, 24-28 October 2004.

DOE 2008a. Remedial Action Work Plan for the Interim Remedial Action for the Volatile Organic Contamination at the c400 Cleaning building at the Paducah Gaseous Diffusion Plant, Paducah Kentucky. DOE/LX/07-0004\&D2 Primary Document, U. S. Department of Energy, Lexington KY.

DOE 2008b. Remedial Design Report, Certified for Construction Design Drawings and Technical Specifications Package, for the Groundwater Operable Unit for the Volatile Organic Compound Contamination at the C-400 Cleaning Building at the Paducah Gaseous Diffusion Plant, Paducah, Kentucky, DOE/LX/07-0005\&D2, U.S. Department of Energy, Paducah, KY, February.

DOE 2005a. Record of Decision for Interim Remedial Action for the Groundwater Operable Unit for the Volatile Organic Compound Contamination at the C-400 Cleaning Building at the Paducah Gaseous Diffusion Plant, Paducah, Kentucky, DOE/OR/072150\&D2/R2, U.S. Department of Energy, Paducah, KY, July.

DOE, 2005b. 2005 End State Vision Annual Update for PGDP, DOE/OR/072119\&D2/R3, U. S. Department of Energy, Lexington KY.

Energy Information Administration (EIA). Average retail price of electricity to ultimate customers by end-use sector, by state. Electrical power monthly with data for April 2007. Available at http://www.eia.doe.gov/cneaf/electricity/epm/table5_6_a.html. 11 July 2007.

Gavaskar, A., M. Bhargava, and W. Condit. Final Report - Cost and Performance Review of Electrical Resistance Heating (ERH) for Source Treatment. Technical Report TR-2279-ENV. Naval Facilities Engineering Command, Engineering Service Center, Port Hueneme, CA.

Johnson, P.C., C.C. Stanley, M.W. Kemblowski, D.L. Byers, and J.D. Colthart, 1990, “A practical approach to the design, operation, and monitoring of in situ soil venting systems," Ground Water Monitoring and Remediation, Spring, pp. 159-177. 
Looney, B., J. Costanza, E. Davis, J. Rossabi, L. Stewart, and H. Stroo, 2007. Review Report: Building C-400 Thermal Treatment 90\% Remedial Design Report and Site Investigation, PGDP, Paducah Kentucky, WSRC-STI-2007-00427, U.S. Department of Energy Office of Scientific and Technical Information, Oak Ridge TN, publically available through www.osti.gov .

Paducah Remediation Services, LLC (PRS). Remedial Design Report, 90\% Design Drawings and Technical Specifications Package, for the Groundwater Operable Unit for the Volatile Organic Compound Contamination at the C-400 Cleaning Building at the Paducah Gaseous Diffusion Plant, Paducah, Kentucky (DOE/LX/07-0005\&D1). April 2007a.

Paducah Remediation Services, LLC (PRS). Remedial Action Work Plan for the Interim Remedial Action for the Volatile Organic Compound Contamination at the C-400 Cleaning Building at the Paducah Gaseous Diffusion Plant Paducah, Kentucky (DOE/LX/07-0004\&D1). May 2007b.

U.S. Army Corps of Engineers (USACE). Design: In Situ Thermal Remediation. Unified Facilities Criteria (UFC). UFC 3-280-05. 31 July 2006.

U.S. Army Corps of Engineers (USACE). Design: In Situ Thermal Remediation. Unified Facilities Criteria (UFC). UFC 3-280-05. 31 July 2006.

van Lookeren, J., 1983, "Calculation Methods for Linear and Radial Steam Flow in Oil Reservoirs,” Soc. Pet. Eng. J., vol. 23, pp. 427-439. 
Appendix A.

Independent Technical Review Team Statement of Work 


\section{STATEMENT OF WORK}

For Review of the Paducah C-400 Electrical Resistance Heating Phase 1 Results and Phase 2 Plans

\section{PURPOSE:}

The U. S. Department of Energy (DOE) is currently operating a three-phase electrical resistance heating treatment system at areas near the southwest corner and east of the C400 Cleaning Building at the Paducah Gaseous Diffusion Plant (Phase 1). DOE is also using the results of Phase 1 to develop plans for implementation of the same technology at areas near the southeast corner of the C-400 Cleaning Building (Phase 2). To better understand the results of Phase 1 and the plans for Phase 2, DOE is soliciting the assistance of a team of experts with expertise in groundwater remediation and treatment, engineering, design, and treatment system installation and operation to review Phase 1 results and Phase 2 plans.

\section{SCOPE:}

The selected team of experts will receive electronically and review background materials concerning the C-400 electrical resistance heating implementation at the Paducah site. After reviewing background material, the team will travel to the Paducah Gaseous Diffusion Plant for a five-day visit, consisting of site tours, briefings, and discussions with the vendor and contractors implementing the electrical resistant heating system. The team is expected to help DOE identify issues that are affecting or could affect the successful implementation of both phases of the electrical resistance heating technology and provide cost-effective solutions and alternatives improving technology implementation. At the close of the site visit, the team will brief DOE and contractor staff on the results of their review. Subsequently, the team will provide a written report summarizing the outcome of the review of Phase 1 results and Phase 2 plans. This written report shall be of sufficient quality that it can serve as a technical assessment of the contractor's progress of the electrical resistance heating treatment at the Paducah site.

\section{TIME AND COST ELEMENTS}

1. Pre-visit document review (estimated 40 hours per team member)

2. Travel to and from the Paducah Gaseous Diffusion Plant

3. Site Visit (estimated 40 hours per team member)

4. Deliverable \#1 - Briefing to DOE and contractor staff at the close-out of the site visit (estimated 4 hours per team member)

5. Deliverable \#2 - Draft written report provided for factual accuracy review (10 to 15 pages maximum; estimated 60 hours per team member)

6. Deliverable \#3 - Final written report (10 to 15 pages maximum; estimated 20 hours per team member) 


\section{ESTIMATED SCHEDULE}

\begin{tabular}{|l|c|c|}
\hline \multicolumn{1}{|c|}{ Action/Deliverable } & Start Date & Completion Date \\
\hline $\begin{array}{l}\text { Contractor Acceptance of } \\
\text { Statement of Work }\end{array}$ & N/A & August 20, 2010 \\
\hline Pre-Visit Document Review & August 25, 2010 & September 8, 2010 \\
\hline $\begin{array}{l}\text { Travel and Site Tour and } \\
\text { Briefings }\end{array}$ & September 13, 2010 & September 17, 2010 \\
\hline $\begin{array}{l}\text { Deliverable \#1 - Briefing to } \\
\text { DOE and contractor staff }\end{array}$ & September 17, 2010 & September 17, 2010 \\
\hline $\begin{array}{l}\text { Deliverable \#2-Draft } \\
\text { Report }\end{array}$ & September 20, 2010 & October 4, 2010 \\
\hline Factual Accuracy Review & October 4, 2010 & October 7, 2010 \\
\hline $\begin{array}{l}\text { Deliverable \#3 - Final } \\
\text { Report }\end{array}$ & October 8, 2010 & \\
\hline
\end{tabular}

Note: Based on current knowledge and assumptions, and subject to change by DOE

Project Manager in consultation with review team.

\section{SELECTION CRITERIA}

1. Demonstrated experience by the team members in groundwater remediation, engineering (construction) of groundwater treatment systems, and implementation of electrical resistance heating treatment.

2. Extensive experience reviewing operating projects, identifying problems, and providing workable recommendations.

3. Ability to meet schedule and price. 
Appendix B

ITR Team Members

Dr. Brian Looney (technical lead), Savannah River National Laboratory

Dr. Joseph Rossabi, Redox-Tech, LLC

Dr. Lloyd (Bo) Stewart, Praxis Environmental, Inc. Short Curriculum Vitae Attached 


\section{Brian B. Looney}

Savannah River National Laboratory, Building 773-42A, Aiken SC

phone: (803) 7253692 or (803) 7252418 (work); (803) 6487784 (home)

fax: (803) 7257673

email: brian02.looney@srnl.doe.gov (work); sclooneyy@yahoo.com (home)

\section{Summary Information}

Dr. Brian B. Looney is a senior fellow engineer at the Department of Energy Savannah River National Laboratory (SRNL) in Aiken SC and an adjunct professor in the Environmental Engineering Science Department at Clemson University. Dr. Looney coordinates development and deployment of innovative environmental characterization and clean-up methods at the Savannah River Site, and serves as a technical advisor supporting the DOE Environmental Management Program.

\section{Education:}

1984 Ph.D. Environmental Engineering, University of Minnesota

1978 B.S. Environmental Science, Texas Christian University

\section{Selected Research Projects:}

2005-2007 Interstate Regulatory and Technology Council (Technical Support to Enhanced Attenuation Team)

2003-2007 Monitored Natural Attenuation and Enhanced Attenuation of Chlorinated Organics (PI)

2003 Aqueous treatment of mercury using chemical reduction and air stripping (PI)

1992-1996 Development of gas phase phosphorus amendment for enhanced bioremediation (PI)

1989-1992 In situ enhanced cometaboloic treatment of TCE using natural gas (PI)

1987-1989 In situ air stripping using horizontal wells (PI)

1986 DOE pilot testing of soil vapor extraction (PI)

\section{Patents:}

Brian holds nine patents related to environmental remediation and characterization. These include:

$4,832,122 \& 5,263,795$ - various applications of horizontal wells for remediation

$5,480,549 \& 5,753,109$ - various application of gas phase phosphorus to support bioremediation

$5,293,931 \& 5,339,694$ - multilevel sampling system and groundwater flow probe

$6,367,563 \& 6,280,625$ - DNAPL collection system and modified airlift recirculation with deep recharge

\section{Selected Awards:}

2006 Citizens for Nuclear Technology Awareness (CNTA) Fred C. Davison Distinguished

Scientist of the Year

2005 - National Groundwater Association Technology Award

2004 - American Chemical Society (ACS) Industrial Innovation Award

2004 - World's Best Technology Award

2000 - Energy 100 Award

1996 \& 2000 - Federal Laboratory Consortium Award for Excellence in Technology Transfer 1996 - George Westinghouse Signature Gold Award

1994 \& 1995 - R\&D 100 Award

\section{Selected Professional Affiliations:}

American Chemical Society, National Groundwater Association, American Society of Civil Engineers, Association of

Applied Geochemists 
SRNL-STI-2010-00176

\author{
Joseph Rossabi \\ Redox Tech, LLC \\ 200 Quade Drive \\ Cary, NC 27513 \\ 919-678-01407/Fax 919-678-0150 \\ E-mail: rossabi@redox-tech.com
}

\title{
Summary Information:
}

Joe Rossabi is principal scientist and part owner of Redox Tech, LLC where he applies innovative remediation solutions, including steam injection, chemical injection (for oxidation or reduction of contaminants), and metals stabilization, to soil and groundwater contamination. Prior to Redox Tech, he was a fellow engineer in the Environmental Sciences and Technology Division of the Department of Energy's Savannah River National Laboratory where he performed applied research and development of environmental characterization and remediation technologies and strategies. His research involved field-testing and implementation of cone penetrometer-based characterization and remediation methods, multiphase flow processes including DNAPL fate and transport, and passive and renewable energy powered methods for characterization and remediation of subsurface contaminants. Licensed Professional Engineer, South Carolina, North Carolina

\section{Education:}

Ph.D., Environmental Engineering and Science, Clemson University, 1999.

MS., Environmental Engineering, University of North Carolina, Chapel Hill, 1991.

MS., Physics, State University of New York, Binghamton, 1985.

BA., Physics, BA., Philosophy, State University of New York, Binghamton, 1982.

\section{Relevant Experience}

Partner: Redox Tech, LLC, Cary, North Carolina, 2004-Present. Chief of operations for soil and groundwater remediation firm specializing in in situ treatment. Redox Tech provides turnkey remediation services. Redox Tech has remediated more than 250 sites with contaminated soils and groundwater using both conventional and innovative technology strategies such as in situ oxidation and reduction with chemical and biological amendments (subsurface injection and blending), steam injection and other strategies.

Fellow Engineer: Environmental Sciences and Technology Department, Savannah River National Laboratory, Westinghouse Savannah River Company, Aiken, South Carolina, 1991-2004.

Research in the areas of subsurface flow, transport, characterization and remediation of contaminated sites. Development/field testing of innovative environmental characterization and monitoring technologies (particularly for DNAPL investigations and cone penetrometer tests). Research/implementation of barometric pumping for characterization, monitoring, and remediation. Teaching of characterization methods and DNAPL fate and transport. National technical review committees and assistance groups including Navy (Direct Push Wells), Paducah (Remedial technologies), Hanford (DNAPL technologies), Los Alamos (Passive Soil Vapor Extraction).

Member of Technical Staff: AT\&T Bell Laboratories; Quest Research Corporation, New Jersey, 1985-1990. Research in the areas of spectroscopic analysis of semiconductors, laser propagation/communications through the atmosphere, optical counter measures, and fiber optic spectroscopy techniques for chemical sensing. 


\section{Licensure, Selected Awards, Patents, Affiliations}

SRTC Laboratory Director's Award (2003);

Westinghouse Savannah River Company President's Award (2003)

George Westinghouse Signature Award of Excellence -3 (1994, 2001); Innovation Award (1997, 1993)

Federal Laboratory Consortium Technology Transfer (1999); Government and Environmental

Sciences Company Innovations Award (1998)

B.G. Lamme Graduate Scholarship Award (1997)

US 6,971,820 - Renewable energy powered, assisted barometric valve.

US 5,641,245; CA 2,221,770; US 6,425,298; US 6,591,700 - Various applications for passive removal of subsurface contaminants.

US 5,775,424; US 5,922,950 - Various applications of multiple depth discrete sampling ports for installation in a single well.

US 5,889,217 - Cone penetrometer process and apparatus for obtaining samples of liquid and gas from soil at discrete depths.

US 6,367,563 - Method and Device for removing a non aqueous phase liquid from groundwater.

American Geophysical Union, National Groundwater Association, National Society of

Professional Engineers, American Water Works Association, Duke University Cancer Protocol

Committee

\section{Selected Publications:}

Rossabi, J., B. D. Riha, J. W. Haas III, C. A. Eddy-Dilek, A. G. Lustig Kreeger, M. Carrabba, W. K. Hyde, and J. Bello 2000. Field tests of a DNAPL characterization system using cone penetrometer-based Raman spectroscopy, Ground Water Monitoring and Remediation, 20 (4), pp 72-81.

Rossabi, J., R. W. Falta 2002. Analytical Solution For Subsurface Gas Flow To A Well Induced By Surface Pressure Fluctuations, Ground Water, 40 (1), pp 67-76.

Rossabi, J., Analyzing Barometric Pumping to Characterize Subsurface Permeability, in Part 2:

Measurement and Monitoring - Gas Transport in Porous Media, eds. C. K. Ho, S. W. Webb, pp 279-290, Springer, The Netherlands, 2006.

Rossabi, J., Subsurface Flow Measurements, in Part 2: Measurement and Monitoring - Gas Transport in Porous Media, eds. C. K. Ho, S. W. Webb, pp 291-302, Springer, The Netherlands, 2006.

Grimm, R.E., G.R. Olhoeft, K. McKinley, J. Rossabi, and B. D. Riha, Nonlinear Complex-Resistivity Survey for DNAPL at the Savannah River Site A-014 Outfall, Journal of Environmental and Engineering Geophysics,Vol 10 (4) pp. 351-364, 2005.

Rossabi, J., B. D. Riha, C. A. Eddy-Dilek, B. B. Looney, and W. K. Hyde, 2003. Recent Advances in Characterization of Vadose Zone Dense Non-Aqueous Phase Liquids (DNAPL) in Heterogeneous Media, Environmental \& Engineering Geoscience, 9 (1) pp. 25-36.

Rossabi, J., T. R. Jarosch, B. D. Riha, B. B. Looney, D. G. Jackson, C. A. Eddy-Dilek, R. S. Van Pelt, and B. E. Pemberton, Determining contaminant distribution and migration by integrating data from multiple cone penetrometer-based tools, in Proceedings of First International Conference on Site Characterization, (ISC '98), Atlanta, GA, Balkema Press, 1998.

Costanza, J., K.D. Pennell, J. Rossabi, and B. Riha. 2002. Effect of Temperature and Pressure on the MIP

Sample Collection Process. In Proceedings of the Third International Conference, Remediation of

Chlorinated and Recalcitrant Compounds, May 20-23, Monterey, CA.

Kram, M. L., A. A. Keller, J. Rossabi, and L. G. Everett, 2001. DNAPL Characterization Methods and Approaches: Part 1: Performance Comparisons, Ground Water Monitoring and Remediation, 21 (4).

Kram, M. L., A. A. Keller, J. Rossabi, and L. G. Everett, 2001. DNAPL Characterization Methods and Approaches: Part 2: Cost Comparisons, Ground Water Monitoring and Remediation, 22 (1).

Rossabi, J., Barometric Pumping: Passive Soil Vapor Extraction, in Chapter 7: Remediation of Organic Chemicals in the Vadose Zone - Vadose Zone Science and Technology Solutions, eds. B. B. Looney, R. W. Falta, pp 970-979, Battelle Press, Columbus, OH, 2000.

Rossabi, J., Cone Penetrometer and Direct Push Tools for Vadose Zone Characterization, in Chapter 3: Vadose Zone Characterization and Monitoring - Vadose Zone Science and Technology Solutions, eds. B. B. Looney, R. W. Falta , pp 186-201, Battelle Press, Columbus, OH, 2000. 
Rossabi, J., Case Study of Cone Penetrometer (CPT)-Based Soil Moisture Probes, in Chapter 3: Vadose Zone Characterization and Monitoring - Vadose Zone Science and Technology Solutions, eds. B. B. Looney, R. W. Falta, pp 428-430, Battelle Press, Columbus, OH, 2000.

Rossabi, J. and R. W. Falta, The behavior of volatile organic contaminants in the vadose zone with respect to barometric pumping and the estimate of residual mass and mass removal using T2VOC, in Proceedings of TOUGH Workshop '98, Lawrence Berkeley National Laboratory, CA, 1998.

Rossabi, J., and B. D. Riha, The Savannah River environmental technology field test platform, in Proceedings of the Instrument Society of America, New Orleans, LA, 1995.

Rossabi, J., B. B. Looney, C. A. Eddy-Dilek, B. D. Riha, and V. J. Rohay, Passive remediation of chlorinated volatile organic compounds using barometric pumping, in Proceedings of the Water Environment Federation: Innovative Solutions for Contaminated Site Management, Miami, FL, 1994.

Rossabi, J., B. W. Jr. Colston, S. B. Brown, F. P. Milanovich, and L.T. Lee, In-situ, subsurface monitoring of vapor phase TCE using fiber optics, in Proceedings of the Third International Symposium-Field Screening Methods for Hazardous Waste and Toxic Chemicals, Las Vegas, Nevada, 1993.

Rossabi, J., and J. S. Haselow, Technology status report: off-gas treatment technologies for chlorinated volatile organic compound air emissions. WSRC-RP-92 473, Westinghouse Savannah River Company, Aiken, SC 29808, 1992.

Venugopalan, S., and J. Rossabi, Raman study of mesogenic transitions in 4,4'-di-npentyloxyazoxybenzene (C5)." J.Chem.Phys. 85(9), 1 November 1986. 


\section{Lloyd "Bo" Stewart}

Praxis Environmental Technologies, Inc., 1440 Rollins Road, Burlingame, CA

phone: (650) 224-3067 or (650) 548-9288 (work)

fax: (650) 548-9287

email: Bo@Praxis-Enviro.com

\section{Summary Information:}

Dr. Lloyd "Bo" Stewart is Vice President and Principal Engineer of Praxis Environmental Technologies, Inc., an applied R\&D company he co-founded in 1992 to bring theoretical concepts into field practice. Dr. Stewart has developed, demonstrated and optimized numerous innovative environmental technologies for characterization and clean-up of chlorinated solvent and petroleum sites at DOD, DOE and industrial sites. Of particular relevance, Dr. Stewart, designed and managed all aspects of the first field demonstration of steam injection below the water table for the cleanup of dense nonaqueous phase liquids (DNAPLs).

\section{Education:}

$1989 \mathrm{PhD}$. Mechanical Engineering, University of California Berkeley

1985 M.S. Mechanical Engineering, Georgia Institute of Technology

1983 B.S. Mechanical Engineering, North Carolina State University

\section{Selected Projects:}

2001-2006 Corrosion of Unexploded Ordnance in Soil Environments, Army Environmental Center (PI)

2003 Rebound Test Procedures and Data Evaluation in Support of Optimization and Closure of Soil Vapor Extraction Systems, Army Corps of Engineers (PI)

2000-2001 Development of Executable Program and Documentation for Public Domain Software to Evaluate Air Permeability Data Collected from Heterogeneous Vadose Zones, EPA (PI) 2000-2001 Theoretical and Experimental Evaluation of Techniques for Passive Maintenance of a Constant Temperature in a Narrow Annular Space Subjected to Transient Heat Loads, Applied Materials (PI) 1999-2001 Implementation and Evaluation of a Novel Approach for Dynamic Characterization and Remediation of Chlorinated Hydrocarbons in the Vadose Zone at Eight Sites on Castle AFB, CA (PI) 1999-2000 Comparison of Field Techniques for Evaluating Soil Permeability and Heterogeneities in the Vadose Zone, EPA (PI)

1998-2000 Field Demonstrations of Techniques for Evaluating and Optimizing Soil Vapor Extraction Systems at Castle, George, Mather, McClellan and Norton Air Force Bases, Air Force Center for Environmental Excellence (PI)

1997-2000 Field Demonstrations of Combined Characterization and Remediation in the Vadose Zone using Pneumatic Well Logging and Soil Vapor Extraction at Beale, Griffiss, and Nellis Air Force Bases, AFCEE (PI)

1997 Theoretical and Experimental Evaluation of Spray Cooling with Phase Change to Maintain a Constant Temperature on a Domed Surface Subjected to Transient Heat Loads, Applied Materials (PI)

1995-1997 Field Demonstration of Steam Injection as an Enhanced Source Removal Technology for Aquifer Restoration, Air Force Research Laboratory (PI)

1995-1996 Develop Public Domain Software and Documentation for Evaluating Potential Lead Migration Problems at Small Arms Ranges for distribution by the Army Environmental Center (PI)

1995 Develop a Generic Work Plan for Performing Remedial Technology Demonstrations at the National Test Sites, for use by Universities and other Researchers unfamiliar with Regulatory Requirements at Hazardous Waste Sites, Army Environmental Center (PI) 1995 Analyze and Model Field Data from a Test of Steam Injection in an Hydraulically Created Fracture, EPA (co-PI) 
1994-1998 Field Demonstration of In Situ Thermally Enhanced Extraction for Restoration of Aquifers Contaminated By Dense Nonaqueous Phase Liquids (DNAPLs), Operable Unit Two, Hill Air Force Base, UT, AFRL (PI)

\section{Patents:}

5,018,576 - Process for the In Situ Remediation of Subsurface Contamination by Combined Steam Injection and Vacuum Extraction (with K. Udell, J. Hunt, and N. Sitar)

\section{Selected Awards:}

Switzer Environmental Fellowship

Tau Beta Pi Engineering Honor Society

\section{Selected Professional Affiliations:}

American Society of Mechanical Engineers, National Groundwater Association, Association of Ground Water Scientists and Engineers, American Institute of Chemical Engineers, American Association for the Advancement of Science

\section{Journal Publications:}

L. Stewart and B. Packer, 2007. Corrosion rates of Carbon Steel, in Soil in Corrosion Science, accepted for publication June 2007.

L. Stewart, 2006. Steady, axisymmetric airflow in a multi-layered vadose zone, under revision for Water Resources Research.

M. Chendorain, L. Stewart and B. Packer, 2005. Corrosion of Unexploded Ordnance in Soil - Field Results, Environmental Science \& Technology, Vol. 39(8), pp. 2442-2447.

R.A. Hodges, R. Falta and 1. Stewart, 2004. Controlling steam flood migration using air injection, Environmental Geosciences, Vol. 11, No. 4, pp. 221-238.

L. Stewart, 2003. Overview of Rebound Test Procedures and Data Evaluation, included as Appendix F to the Army Corp of Engineer's Soil Vapor Extraction and Bioventing Engineer's Manual, Omaha, NE L. Stewart and K. Udell, 1988. Mechanisms of Residual Oil Displacement by Steam Injection, SPE Reservoir Engineering, Vol. 3, pp. 1233-1242, November 1988.

\section{Selected Conference Proceedings:}

"Field Demonstrations of Thermally Enhanced Extraction," Proceedings, Abiotic In Situ Technologies for Groundwater Remediation Conference, August 31 - Sept 2, 1999, Dallas, TX, EPA/625/R-99/012, August 2000.

"Field Demonstration of Thermally Enhanced Extraction for DNAPL Source Removal," with J. Ginn and S. Hicken, in Nonaqueous-Phase Liquids: Remediation of Chlorinated and Recalcitrant Compounds, Wickramanayake and Hinchee (Eds.), Battelle Press, Columbus, OH, 256 pp., 1998.

"Combined Steam Injection and Vacuum Extraction for Aquifer Cleanup," with K.S. Udell, presented at the Annual Meeting of the International Association of Hydrogeologists, Calgary, April 1990.

"The Effects of Gravity and Multiphase Flow on the Stability of Steam Condensation Fronts in Porous Media," with K.S. Udell, Multiphase Transport in Porous Media, ASME HTD Vol. 127, December 1989. "Mechanisms of In Situ Remediation of Soil and Groundwater Contamination by Combined Steam Injection and Vacuum Extraction," with K.S. Udell, Paper No. 119d presented at the Symposium on Thermal Treatment of Radioactive and Hazardous Waste at the AIChE Annual Meeting, San Francisco, November 1989.

"The Effect of Gravity on Steam Propagation in Porous Media," with K.S. Udell and M.D. Basel, Multiphase Transport in Porous Media, ASME HTD Vol. 91, December, 1987. 


\author{
Walter L. Richards \\ Performance Results Corporation (PRC) - Paducah Site \\ phone: (270) 441-6839 \\ fax: (270) 441-6801 \\ email: walt.richards@lex.doe.gov
}

Mr. Richards has over thirty years of engineering experience with Environmental and Chemical Engineering projects. He has been responsible for the management, assessment, design and construction of various chemical, industrial and environmental remediation projects. Some of these include chemical engineering projects, natural gas drilling, production and development projects, and environmental remediation projects in air water and wastewater treatment. Some of these projects include radionuclide capture and treatment in the component and process designs. He is a licensed Professional Chemical Engineer in the states of California, Florida and South Carolina. Mr. Richards has both a Master of Science in Engineering degree and Bachelor of Science in Engineering degree from Southern Illinois University in Carbondale, Illinois. 


\section{Appendix C}

Synopsis of Pre-Deployment Recommendations from the DOE Independent Technical Review (Looney et al., 2007) and PGDP Resolutions 


\section{$\underline{\text { Review of Consolidated List of Recommendations }}$}

The consolidated list of recommendations from the ITR report of August 2007 is presented below with an assessment of the response to the recommendations. The assessment of the response is provided in italicized red font. The list of consolidated recommendations provided a snapshot of the various recommendations in a single listing to assist PPPO and their contractors in implementing TCE source removal near the C-400 Building. While all of the recommendations were important, the 2007 ITR team considered the recommendations that are marked with a bold number to be critical. They noted that: "These should be adequately addressed and resolved prior to moving forward with the full scale implementation (for those recommendations with multiple subsidiary recommendations, all of the subsidiary recommendations are considered critical if the overarching number is bold)." Many of the critical recommendations were "Partially done" in implementing the Phase I implementation and a few were "Not done." The poor heating performance in the high permeability RGA, one of the key lessons learned from Phase I, is tracable to the lack of adequate response to the critical recommendations from the 2007 ITR. Several of these critical topics (most importantly weaknesses in the modeling and simulation and cost control) have not been adequately addressed and, thus, have the continued potential to adversely impact discussions and decisions related to Phase II.

\section{Site investigation and target zone delineation}

5.1.1 The ITR team determined that the target zone delineation should be modified based on data collected during system installation and based on key data from the $90 \%$ RDSI. The target zone was modified (but insufficient data were collected to adequately support the effort) --Partially done.

5.1.1a Collect soil and groundwater samples during the installation of the ERH boreholes with the specific goals of evaluating the MIP dataset and refining the treatment volume. Once the dataset is validated, then the treatment volume can be refined to address areas where TCE DNAPL may be present. This may involve an increase in the lateral and vertical extent of the thermal treatment volume in the Southeast source zone area, and possibly in the source zone area to the east. Although some soil samples were collected when installing the ERH boreholes, they were inadequate (too few samples with unrepresentative spacing) for evaluating the MIP data set and refining the treatment volume. This has led to serious challenges in refining and improving estimates of initial target TCE mass - Partially Done.

5.1.1b Increase the vertical extent of the thermal treatment volume in the Southwest source zone area into the low permeability McNairy. Data collection should be integrated into the installation with the contingency to expand both the treatment target zone (e.g., up to $15 \%$ ) by adding electrodes either below or laterally, and the associated recovery systems. Some boreholes should be extended through the RGA to the McNairy interface in each treatment area. No electrodes were placed into the McNairy despite the 
strong recommendations of the ITR team. Electrodes were installed to the bottom of the RGA. - Partially done. 
5.1.2 Install additional ground water monitoring wells (multiple depths and locations) to provide the basis for assessing the broader impacts of the Building C-400 remediation on the overall PGDP groundwater plume(s). Consider monitoring well clusters closer to the C-400 building on both the east side and northwest corner and multiple screened intervals (at least two screen intervals in the RGA and a screen in the UCRS). Several additional well clusters were installed. - Done.

5.1.3 Additional characterization beneath and to the north of the C-400 Building is needed to determine if the high concentrations that have been measured are due to the "known" upgradient sources or if substantive TCE DNAPL is beneath the footprint of the building. If substantive TCE DNAPL is identified beneath the building, then additional response actions to remove source may be needed to further mitigate contaminant mass transferred to the groundwater plume(s). Characterization and response actions will require coordination with Building C-400 activities and plans. This activity was deferred to the future - Not Done.

5.1.4 PGDP should assess the potential for co-contaminants by reviewing process records and analytical results and, if necessary, develop a conceptual model for their behavior during heating. The ITR team supports basing the remediation system design and operation, as well as the waste handling, primarily on the TCE DNAPL and the mass reduction. Trace levels of 99Tc were encountered in the condensed DNAPL but were determined to be below regulatory criteria for additional treatment. PCB analyses have been performed on some groundwater samples but not on the recovered DNAPL where it is most likely to occur in higher concentrations. - Partially Done.

\section{Performance objectives}

5.2.1 The temperature criteria above the water table should be based on exceeding the boiling point of the TCE DNAPL. The temperature criteria below the water table should be based on the boiling point of water at the nominal local conditions (approximately $100^{\circ} \mathrm{C}$ at the water table, $125^{\circ} \mathrm{C}$ at a depth of 50 feet below the water table, etc). The criteria appeared to be set according to recommendations but were not met in the RGA Done.

5.2.2 The operational monitoring and stopping criteria for this project should be technically based and developed to assure that performance objectives are met and that the system is operated efficiently. -Partially Done

5.2.2a Do not tie the shut down criteria to any particular vapor phase concentration (rather develop an integrated approach as described in 5.2.3b and 5.2.3c). The 400 ppmv criterion in the vapor phase was not changed but additional performance objectives were used to develop shut down criteria. -Partially Done. 
5.2.2b Use asymptotic behavior as an indicator of the status of the C-400 source cleanup but use the "weight of evidence" of additional criteria to specify operational actions. Additional criteria could be mass removal rate, cost of removal comparison (i.e., $\$ / 1 b$ daily continued operation ERH/SVE versus $\$ / \mathrm{lb}$ for P\&T or cut off wall, or another potential future remedial action), mass of TCE remaining in the C-400 source area compared with the mass already in the plume or from other sources, or mass release rate from residual source balanced against separately measured attenuation rates within the downgradient plume. Some additional criteria were used but a comprehensive analysis of the benefit of continued operation in comparison with other methods was not performed. -Partially Done.

5.2.2c Identify and use site wide remedial goals to permit bounding calculations and a context for C-400 specific stopping criteria. A comprehensive analysis of the benefit of continued operation in the context of site wide goals was not performed. -Not Done.

5.2.3 Individual termination criteria should be developed for key target zones in the UCRS and RGA and applied to operations in each of the three treatment areas. -Partially Done

5.2.3a Individual termination criteria should be developed for the UCRS and RGA in each of the three treatment areas. - Not Done

5.2.3b Performance metrics should include groundwater concentrations and groundwater concentration trends/behaviors within the treatment area to indicate the extent of treatment that has been achieved and to aid in determining when the system should be shut down. We are awaiting the latest data but have not seen analyses of groundwater concentration trends. -Partially Done

5.2.3c The performance criteria for the ERH, the SVE and the water extraction should be decoupled (and necessary monitoring added to the system). Continued operation of the SVE system in the vadose zone should be considered even after the site cools if a costeffective mass removal rate is achieved. Current plans call for continued operation of SVE and groundwater recovery and termination of power to electrodes. -Partially Done

5.2.4 Include vacuum and temperature monitoring around the treatment areas to aid in determining that hydraulic and pneumatic capture is being achieved and maintained during the remediation. Multilevel temperature and pressure monitoring devices were installed but there were insufficient locations to accurately assess heating extent. In contour plots of temperature, the temperature contributions of the electrode points are over-weighted and provide an unrealistic depiction of the extent of heating. -Partially Done 
5.2.5 Measure effluent contaminant levels coming from the near surface areas that are being treated by SVE only separately from effluent vapors coming from the heated zone. -Not Done

\section{Project and design topics}

5.3.1 The risk of full scale implementation should be mitigated by phasing or by assuring acceptable operational responsiveness and flexibility. Although the heating was broken into two phases, no electrodes were installed specifically in the McNairy so deep heating of that lower permeability zone was not tested . -Partially Done

5.3.2 The separate steam injection in the area of the ERH treatability study site should be eliminated from design. Steam heating was eliminated from the design for phase 1 but was incongruously suggested by the contractors for phase 2. -Done

5.3.2a The separate steam injection in the area of the ERH treatability study site should be eliminated from design. The team believes that the primary ERH grid should be expanded and that the former electrodes should be removed by overdrilling if necessary. -Done

5.3.2b If the steam injection well remains in the system, extraction wells for hydraulic and pneumatic control must be included around the entire injection well to avoid a redistribution of contaminants to outside of the treatment area. $-N / A$

5.3.3 The design modeling need to be revised and additional assurances provided that the heating objectives will be met. - Not Done

5.3.3a Revise design model and use the soil permeability values provided by the site geologist. Although a value of permeability from previous site documents was used, an appropriate range of permeability values (including high values suggested by the ITR) was not used. This led to poor heating performance in the RGA explicitly predicted by the ITR. -Not Done

5.3.3b Revise the model boundary conditions in the saturated zone and use a specified head boundary. - Not Done

5.3.3c Provide water and contaminant mass balances to assure that the model is conforming to the PGDP consensus conceptual model for the site. For uncertain inputs and issues such as heterogeneity, perform more sensitivity studies to help design sufficient flexibility in to the design and reduce project risks. Although water mass balances were performed, the model was not sufficiently revised to conform to the PGDP consensus conceptual model of the site. -Not Done

5.3.3d Revise the vadose zone boundary conditions to be more realistic (see also separate SVE issue). - -Not Done 
5.3.3e The detailed soil electrical conductivity data collected by the MIP during the RDSI should be used to ether confirm or refine the assumed values and perhaps to better incorporate heterogeneity (e.g., low electrical conductivity measured in samples from the lower RGA) into the model. We saw no evidence that the extensive electrical resistivity data set was used to either refine the operations or predict performance. However, the post test temperature and power data appear to conform to the electrical resistivity data collected with Geoprobe tool . -Not Done

5.3.3f Significant uncertainty remains related to the electrode spacing and design for this high permeability setting. Since the primary basis for documenting the design and the projected ability to reach temperature is the numerical modeling by the contractor team, the ITR team recommends that the contractor team stand behind the heating performance predictions (i.e., guarantee that temperature requirements will be met and make adjustments and modifications as necessary without additional cost to DOE). The uncertainty in the numerical modeling was not reduced, no performance guarantee was provided, and the contractor has provided the same unsuccessful basis (with a slight modification increasing groundwater flow to a value that may be too low) for phase 2. Not Done

5.3.4 The ITR team advocates a staged system startup and shut down. An insufficient time was allowed for SVE and groundwater extraction prior to powering the electrodes so an adequate baseline for extraction could not be determined . - Partially Done

5.3.4a Once the heating of the RGA has been initiated, every effort should be made to keep that system running until the remediation of the RGA is complete. Although there were some problems with equipment, it appears that efforts were made maintain system operations until shutoff was determined. The remediation of the RGA was not complete, however. - Partially Done

5.3.5 The system should be designed with sufficient flexibility to respond to field conditions. - Partially Done

5.3.5a Final placement of electrodes and other infrastructure should be based on field measurements (e.g. of lithological contacts at the installation location) rather than on predetermined depths on drawings. We saw minimal efforts to adapt electrode and sensor emplacement to field observations. - Partially Done

5.3.5b Add electrodes to address target TCE DNAPL contamination that is beyond the current design boundaries. Additional electrodes were installed but since additional characterization (both to calibrate MIP data and to refine contaminant extent) was not adequately performed, targeting of heating to the extent of TCE DNAPL could not be determined. - Partially Done

5.3.6 The basis for the SVE design should be improved and documented. We saw no substantive efforts to improve and document the SVE design. - Not Done 
5.3.6a Perform a combined SVE pilot test (e.g., 48 hours) and air permeability test to allow proper design of a vapor extraction and treatment system. - Not Done

5.3.6b Design for operation of the SVE system in the vadose zone for the periods both before and after the operation of the ERH system in the deeper soils and groundwater. SVE operation was not sufficiently performed before ERH but will be continued after ERH. - Partially Done

5.3.7 Develop a detailed monitoring plan that is linked to the performance metrics. This plan should describe what media are to be sampled, where the samples will be collected and how the samples will be used to assess performance. The location and deign of the sampling ports and access points should be specified in the design and construction documents. Information that was provided contained minimal information on how the collected data would provide a compelling assessment of performance. As a result, the assessment of the performance of Phase I may be subject to ambiguity and controversy. - Partially Done

5.3.8 Modify the design and implementation, as appropriate, based on the ITR team observations. We saw little evidence that the most relevant observations of the ITR team were incorporated into a modified design and implementation (e.g. related to heating the deep portion of the RGA). - Not Done

5.3.9 Expand and improve contingencies by considering a broader array of technologies and responses. During this process, encourage the engineers, regulators and managers involved to develop diverse and creative options. Consider the ITR team observations and suggestions in developing the expanded contingencies. Additional contingencies were developed as a part of the O\&M Plan and the RAWP - note that the contingencies lacked the diversity recommended in the initial ITR report and many of these consisted of increasing power. - Partially Done

\section{$\underline{\text { Health and safety }}$}

5.4.1 Trained ERH personnel with significant experience should be onsite to install electrodes and infrastructure (construction), and to oversee operations throughout the duration of the project. Contractor personnel have not been onsite to oversee operations throughout the duration of the project. - Partially Done

5.4.2 Monitor ${ }^{99} \mathrm{Tc}$ and incorporate contingencies in the equipment operations and waste handling. Although monitoring of the ${ }^{99} \mathrm{TC}$ was performed, no contingencies in operation were developed prior to operation. - Partially Done 
5.4.3 Monitor for radon and other hydrophobic contaminants that might be present and incorporate contingencies in the equipment operations and waste handling, if necessary.

${ }^{99}$ Tc was measured in the groundwater and DNAPL. PCBs were measured in groundwater but not in DNAPL. Radon was not monitored. - Partially Done

5.4.4 Develop documentation and descriptions of process system interlocks and a more complete evaluation of failure scenarios (i.e., how systems and components interact in a variety of failure modes). This was provided in the O\&M Plans and RAWP. -Done

\section{Cost, contracting, and cross cutting}

5.5.1 Further refine and reduce costs, where possible, as design is finalized. The ITR team determined that the estimated cost for ERH thermal treatment at the C-400 Building is within the range of thermal treatment costs at other federal sites on a per treatment volume and per electrode basis. Nonetheless, the cost is near the upper end of the historical range and further cost refinement and cost reduction opportunities should be pursued as the project plans are finalized. Current costs for this project significantly above initial estimates and all other heating projects to date. While some of the specific recommended actions were implemented (e.g., getting drilling costs closer to industry norms) other aspects of the work were allowed to expand (i.e., further cost reduction opportunities were not vigorously pursued) - Not Done

5.5.1a The costs for waste management and disposition are a significant fraction of the overall estimated project costs. With a treatment and disposal cost on the order of $\$ 1,000$ per 55-gallon drum of solid waste, the importance of properly labeling, tracking, and categorizing each of the anticipated 1,400 drums should be a priority. Because the recovery of DNAPL and other waste has been significantly less than anticipated, this has not been a major issue. -Done 
5.5.1b Consider recycle of collected DNAPL. Currently, the 75,000 gallons of TCE DNAPL expected to be recovered from the subsurface as the result of thermal treatment operations is designated for off-site treatment and disposal. The ITR team recommends considering solvent recycling as an option rather than disposing of the TCE DNAPL as hazardous waste. Solvent recycling was incorporated into the treatment but has been hampered by the potential for co-contaminants and may not be cost-effective at this site. -Done

5.5.2 Consider identifying preferred technology classes (e.g., thermal) rather than a specific variant (e.g. ERH) unless there is a compelling reason to select the variant. No Phase I response needed $-N / A$

5.5.3 A data sharing, reporting and communication plan should be developed to maximize the potential for success Some data reporting on line (temperature, power, pressure) has been incorporated but much of the data necessary for evaluating the performance of the project is not easily accessible. - Partially Done

5.5.4 The ITR team recommends that PGDP identify the basis for selecting the ERH provider to facilitate effective and timely initiation of the C-400 Building Area TCE DNAPL removal. The basis for sole sourcing the contractor (selective electrode control) has not provided an advantage in attempting to achieve the objective of heating in the RGA . - Partially Done

5.5.5 The technology provider should have an active role in all phases of implementation (construction and start-up) and throughout the operational campaign. The technology provider has been actively involved in the project. -Done 